Article

\title{
Energy-Based Novel Quantifiable Sustainability Value Assessment Method for Machining Processes
}

\author{
Aqib Mashood Khan ${ }^{1,2}{ }^{(0}$, Saqib Anwar ${ }^{3}{ }^{-}$, Munish Kumar Gupta ${ }^{1,4}$, Abdullah Alfaify ${ }^{3}{ }^{(0}$, \\ Saqib Hasnain ${ }^{5}$, Muhammad Jamil ${ }^{2}$ (D), Mozammel Mia ${ }^{6, *(1)}$ and Danil Yurievich Pimenov ${ }^{4}$ \\ 1 Key Laboratory of High Efficiency and Clean Mechanical Manufacture, Ministry of Education, \\ School of Mechanical Engineering, Shandong University, Shandong 250061, China; \\ dr.aqib@nuaa.edu.cn (A.M.K.); munishgupta@sdu.edu.cn (M.K.G.) \\ 2 College of Mechanical and Electrical Engineering, Nanjing University of Aeronautics and Astronautics, \\ Nanjing 210016, China; engr.jamil@nuaa.edu.cn \\ 3 Industrial Engineering Department, College of Engineering, King Saud University, P.O. Box 800, \\ Riyadh 11421, Saudi Arabia; sanwar@ksu.edu.sa (S.A.); aalfaify@ksu.edu.sa (A.A.) \\ 4 Department of Automated Mechanical Engineering, South Ural State University, Lenin Prosp. 76, \\ 454080 Chelyabinsk, Russia; danil_u@rambler.ru \\ 5 Depertment of Mechatronics Engineering, University of Engineering and Technology Taxila, \\ Taxila 47050, Pakistan; engrsaqibhasnain@hotmail.com \\ 6 Department of Mechanical Engineering, Imperial College London, London SW7 2AZ, UK \\ * Correspondence: m.mia19@imperial.ac.uk
}

Received: 2 November 2020; Accepted: 20 November 2020; Published: 23 November 2020

check for updates

\begin{abstract}
Sustainability assessments of cooling/lubrication-assisted advanced machining processes has been demanded by environment control agencies because it is an effective management tool for improving process sustainability. To achieve an effective and efficient sustainability evolution of machining processes, there is a need to develop a new method that can incorporate qualitative indicators to create a quantifiable value. In the present research work, a novel quantifiable sustainability value assessment method was proposed to provide performance quantification of the existing sustainability assessment methods. The proposed method consists of three steps: establishing sustainable guidelines and identifying new indicators, data acquisition, and developing an algorithm, which creates the Overall Performance Assessment Indicator (OPAI) from the sustainability assessment method. In the proposed algorithm, initially, both quantitative and qualitative sustainability indicators are normalized. After weight assignment and aggregation, the OPAI is obtained. The developed algorithm was validated from three literature case studies, and optimal cutting parameters were obtained. The present methodology provides effective guidelines for a machinist to enhance process performance and achieve process optimization. The study also offers a relationship between sustainable and machining metrics for the support of industrial sustainability.
\end{abstract}

Keywords: sustainability; Overall Process Assessment Indicator (OPAI); sustainable machining; energy consumption; environmental impact; machining costs; waste management

\section{Introduction}

The development of sustainable manufacturing processes is becoming inevitable for the manufacturing industry. Sustainability does not solely address environmental issues; it also concerns social equity and economic development.

Production time, electrical power and energy consumption, production cost, carbon emissions, waste management, personal health and safety, and water consumption are the major sustainable metrics [1]. The machinability factors include surface quality, cutting force, cutting temperature, residual stresses, 
and chip characteristics. Each sustainability factor further consists of sustainability indicators. Sustainability indicators (SIs) are the quantitative or qualitative measures of the sustainability performance of products or manufacturing processes in terms of sustainability aspects. The SIs are classified into two categories, i.e., quantitative indicators and qualitative indicators. The quantitative indicators include $\mathrm{CO}_{2}$ emission, electrical power and energy consumption, and production cost [2]. These indicators can be measured physically using instruments or calculated by using equations. However, qualitative indicators are assessed via expert opinion, International Organization for Standardization (ISO) standards, and surveys. It includes personnel health risks, safety, and customer satisfaction.

The sustainable value creation of products and services has become essential. Sustainable values consist of economic, environmental, and societal values. Economic values are relatively easy to calculate. However, environmental and societal values are difficult to obtain from the perspective of manufacturing processes. It is very difficult to define and establish a methodology for the value assessment of societal and other qualitative indicators. Mechanical machining is a widely used operation in the manufacturing industry. Thus, developing a sustainable value framework for advanced lubrication/cooling (lubricooling)-assisted machining processes will be a very effective tool for a machinist.

Initially, it is necessary to understand the existing methods of sustainability assessment since there is a dire need to develop sustainable guidelines based on the triple-bottom approach (TBC), 6R, life-cycle assessment (LCA), and energy, environment, economy (3E) methods. Therefore, it is an essential task to quantify sustainable value generation, which requires the quantification of environmental and societal metrics. The sustainable metrics were selected from the guidelines to develop a sustainability performance evaluation methodology. The proposed methodology defines sustainability metrics based on sustainable guidelines to evaluate the Overall Performance Assessment Indicator (OPAI) at the process level.

\section{Literature Review}

During the manufacturing processes, machine tools, workers, and equipment come together to add value to the material and produce mechanical parts. Machining is a key process in the manufacturing domain. The performance of machining processes from the machinability perspective has been studied by many scholars [3,4]. It is very difficult to machine hard materials, such as Haynes and titaniumand nickel-based alloys. These alloys are used in the aerospace and military industries. In the past, authors have proposed various technological measures to improve the machinability of difficult-to-cut materials [5].

Jawahir and Jayal [6] proposed a new methodology for the assessment of sustainability dimensions of the machining process. The authors used empirical and analytical techniques to develop their algorithm to predict the sustainability elements of machined products. Badurdeen et al. [7] introduced a new approach for sustainable supply chain management (SCM) based on the total life cycle of a product. Unlike conventional practices, the new approach also included recovery, redesign, and remanufacture stages. Joshi et al. [8] proposed a new closed-loop $6 \mathrm{R}$ methodology for sustainable manufacturing. The $6 \mathrm{R}$ approach added three more new stages to the recovery, redesign, and remanufacture stages in the traditional approach. Jawahir et al. [9] worked on the $6 \mathrm{R}$ methodology for sustainability assessments in manufacturing processes. However, the authors did not quantify the qualitative indicators. Feng et al. [10] defined the sustainability-related guidelines of a product for its entire life cycle. The authors considered the stock material preparation, manufacturing, distribution, customer use, and post-use stages to investigate three universal aspects of the TBC. General guidelines for sustainable products were already available in the literature. However, Fiksel et al. [11] gathered holistic data from various companies and established quantification values through a sustainability performance measurement framework. The framework was based on three aspects, i.e., the triple-bottom approach, resource consumption, and the full life cycle. 
Pusavec and Kopac [12] highlighted the main sustainability indicators, i.e., waste management, environmental issues, electrical energy consumption, machining costs, and personal health and operational safety. In addition, the authors calculated the production cost of dry and cryogenic-assisted machining processes. Reich-Weiser et al. [13] mainly focused on the sustainability assessment of a material processing industry (GM Motors). The authors established a top-down approach that highlighted the sustainability metrics, including environmental-cost- and energy-consumption-related metrics. In the past, several sustainability performance rating systems have been designed. For example, the Global Report Initiative (GRI) consists of 70 indicators, and the Ford Product Sustainability Index was proposed based on 8 indicators [14].

Khan et al. [2] conducted external turning experiments as part of holistic investigations of the nanofluid-assisted machining process. In the experimental study, the authors developed novel empirical models based on the energy, environment, economy (3E) approach. In another study, Priarone et al. [15] used the $3 \mathrm{E}$ approach to find optimal cutting parameters for the conventional emulsion-assisted machining process. Optimal cutting parameters were found for electrical energy demand, production time, cost, and carbon emissions. However, the authors did not address waste management and personal health and safety. Khanna et al. [16] conducted cryogenic-ultrasonic-assisted turning (CUAT) and cryogenic-assisted turning (CAT) experiments for the machining of Nimonic- 90 alloys and investigated the sustainability and machinability aspects. Results revealed that $20 \%$ less energy consumption and $\mathrm{CO}_{2}$ was emitted from CUAT as compared to CAT. In another study, Khanna et al. [17] reduced power consumption from the ultrasonic-assisted turning of Nimonic-90 alloys. The authors used a hybrid particle swarm with simplex methods (PSO-SM), where it was found that the proposed machining method can reduce the electrical power consumption by $8-10 \%$ when compared with ordinary turning. Agrawal et al. [18] developed a new cryogenic-ultrasonic minimum quantity lubrication-assisted machining setup and used traditional methodology for the analysis of sustainability and machinability aspects. The results showed that the proposed hybrid cooling approach improved sustainability during Ti-6Al-4V turning.

A state-of-the-art review paper on the holistic energy consumption of machine tools was published by Khan et al. [19]. The review paper reported on various aspects of energy reduction strategies. Mia et al. [20] considered cutting energy, surface quality, and productivity as response parameters. In addition, the authors used an LCA of cryogenic liquid nitrogen $\left(\mathrm{LN}_{2}\right)$-assisted machining. Numerous efforts are also made for the reduction of $\mathrm{CO}_{2}$ emissions from the machining process. Sing et al. [21] compared the electrical energy consumption and carbon emissions between Ranque-Hilsch vortex tube (RHVT) and conventional Minimum Quantity Lubrication MQL-assisted machining processes. The results showed that RHVT has the potential to reduce carbon emissions by 45 to $56 \%$ in contrast with conventional MQL. The economic pillar of the TBC approach was also studied by many researchers. In a recent study, Khan et al. [22] investigated the production of dry machining and mono and hybrid nanofluid-assisted machining processes. Their results showed that the hybrid nanofluid-assisted machining processes produced $4.7 \%$ less $\mathrm{CO}_{2}$ compared to conventional machining methods.

The abovementioned literature reviews mainly focused on either machinability- or sustainability-based investigations of machining processes. Most of the studies were published on conventional, dry, or emulsion-assisted machining. Finding a set of optimal cutting parameters for advanced lubricooling-assisted machining processes has become inevitable. There is a dire need to include sustainability indicators that consider resource consumption as well. For example, energy consumption and carbon emissions from nanofluid and liquid nitrogen have not been addressed before.

Researchers have investigated the sustainability assessment of many manufacturing processes. However, integrating the machinability and sustainability aspects to generate a quantifiable sustainability value is very necessary for understanding the process performance. According to the authors' best knowledge, sustainable value creation for the advanced lubricooling-assisted machining 
processes has not been addressed in the past. This research work covered (1) establishing sustainable guidelines for sustainable (dry, nanofluid- and cryogenic-assisted) machining processes, (2) developing an energy-integrated heuristic algorithm for sustainable machining, (3) quantifying environmental and societal indicators to generate a quantifiable sustainability value, and (4) model validation through three case studies.

\section{Measuring the Sustainability Value of a Machining Process}

The word sustainability can be defined as "development that meets the needs of the present without compromising the ability of future generations to meet their own needs." Various methods have been adopted to evaluate the sustainability of the machining process. Each study contains a different set of metrics to evaluate sustainability, which makes this process complex.

A synergistic and holistic analysis is usually performed for the evaluation of the sustainability of a machining process. Sometimes, the life cycle assessment of production has been used as a sustainability assessment of the machining process. Several elements can be studied for the sustainability assessment, which are shown in Figure 1.

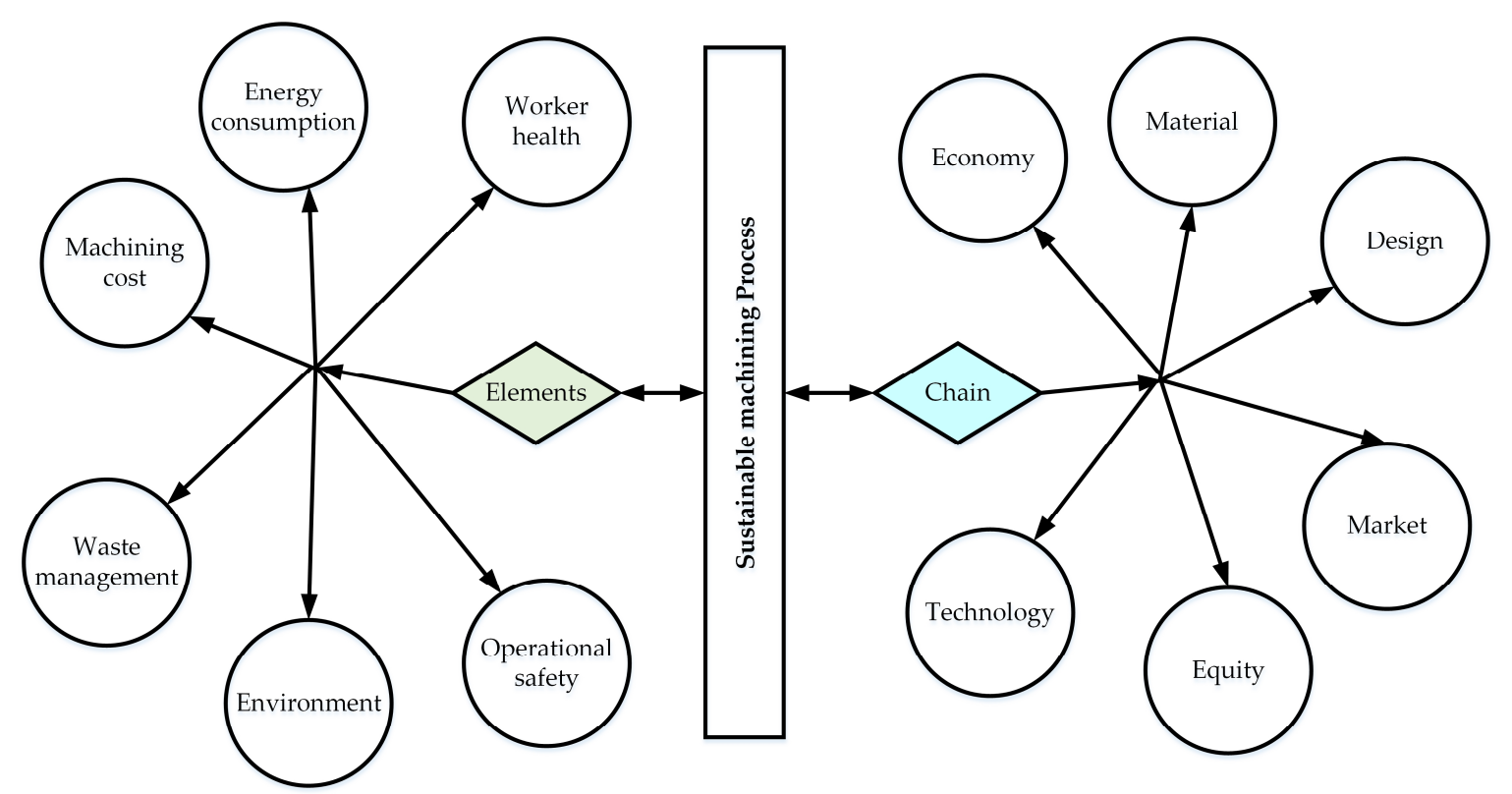

Figure 1. Fundamental elements of a sustainable machining process and the chain of product sustainability [6].

In the past, researchers studied the machining process from a sustainability point of view and made sure the process should have a lower environmental burden, be eco-benign, be harmless to worker health, and most importantly, it must be economical. The sustainability of the process also mainly depends upon the system boundary selected. If the system boundary is small, only a few indicators can be selected for the process evaluation [23]. For a holistic analysis, four stages are commonly considered, namely, acquisition of raw material, manufacturing, use/reuse, and recycle and waste management.

The National Council for Advanced Manufacturing (NACFAM) accentuated the "sustainable" products and "sustainable manufacturing" in the metal processing industry [24]. In another study, it was stressed that sustainable manufacturing must improve not only the resource and machine tool energy but also reduce environmental impacts. Furthermore, it must offer greater safety and produce minimal waste without compromising the quality of the workpiece [6]. In the past, researchers used the three following major concepts repeatedly to evaluate the sustainability of the specific process. 


\subsection{R Approach}

The six stages named reduce, reuse, recycle, recover, redesign, and remanufacture are often called the $6 \mathrm{R}$ approach. The stages demonstrate the material flow through the system boundary. The $6 \mathrm{R}$ approach starts with reduce, which emphasizes the reduction of resource consumption. For example, recently, advanced manufacturing technologies have been proposed that can reduce resource consumption without compromising process efficiency. This approach also emphasizes the reuse and recycling of products, which can reduce the severe impacts of energy-intensive processes on the environment. Redesigning the already built technology is essential for improving the performance of the process. During the redesign stage, the environmental burden of the products and the process are considered. Similarly, natural resources, energy, and costs can be saved by remanufacturing the products. Hence, the $6 \mathrm{R}$ approach is an effective way to analyze the sustainability of the process. However, it is necessary to quantify the sustainable values of the $6 \mathrm{R}$ approach. The concept of the $6 \mathrm{R}$ approach is shown in Figure 2.

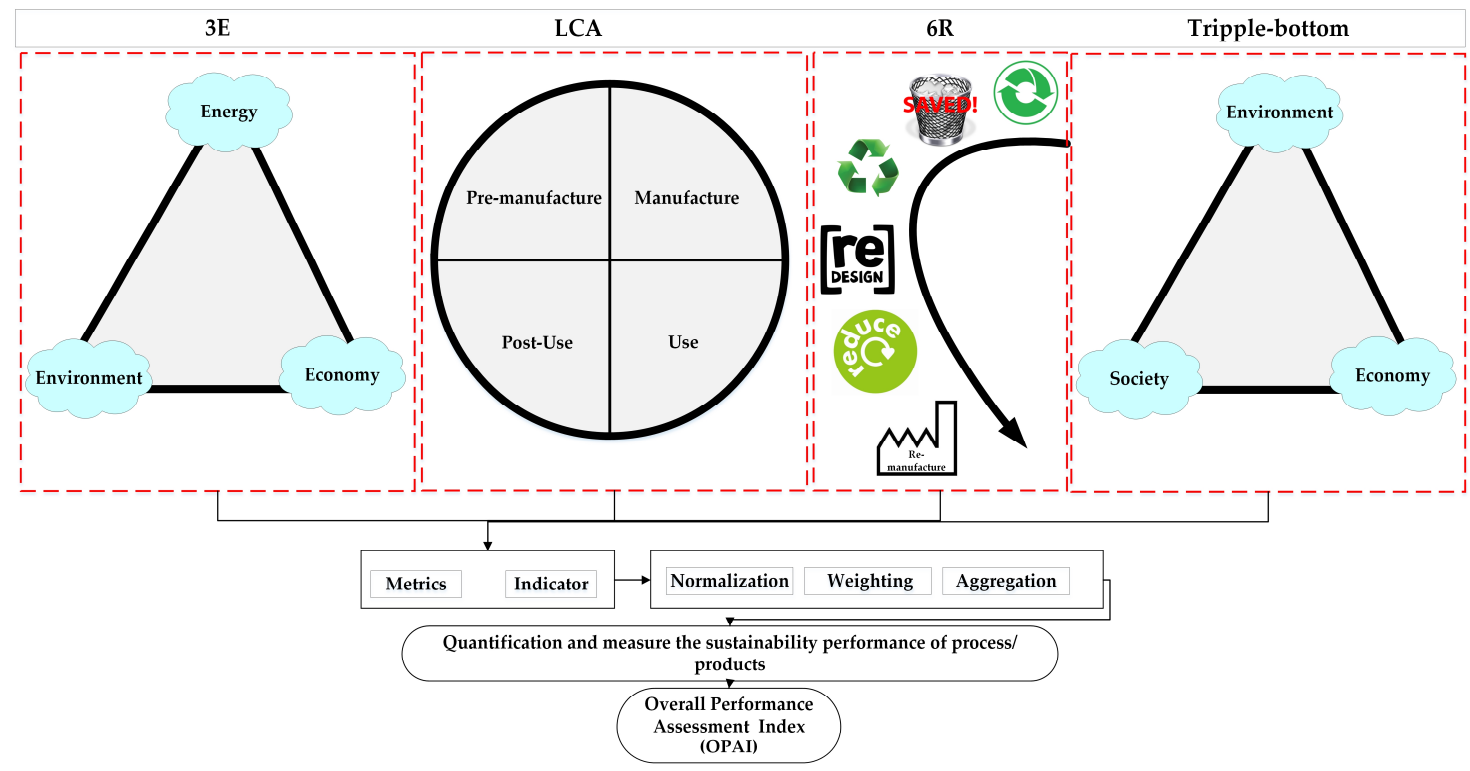

Figure 2. Methodology for the quantification of sustainability values of the process.

\subsection{Triple-Bottom Approach}

In conventional practice, only the manufacturing cost is evaluated, and based on this cost estimation, the environmental and societal impacts are assessed. However, a TBC works in a holistic system and considers the economic, environmental, and societal aspects as three fundamental pillars of sustainability. A separate sustainable value for each metric can be achieved for the environmental and economic impacts of a specific process.

The manufacturing process needs renewable and non-renewable resources to produce industrial products for the welfare of society. The triple bottom line makes sure that the resource consumption is low to reduce the process's impact on society and the environment. In the past, researchers evaluated the triple-bottom approach as a qualitative tool analysis [7]. However, it is necessary to develop a state-of-the-art heuristic algorithm that can quantify sustainability values. The triple-bottom approach is displayed in Figure 2.

\subsection{Life-Cycle Assessment}

Cradle-to-grave analysis of discrete part production is often performed by considering the total life-cycle assessment, which includes four stages: pre-manufacturing, manufacturing, use, and post-use, as highlighted in Figure 2. In an LCA, each phase deals with various processes and it 
needs to incorporate various stakeholders. Thus, the sustainability assessment of each phase depends upon its factors and the average impact of all phases is taken into consideration to evaluate the process. The various environmental effects of products and services are quantified and compared, the obtained results are used to make the best decision and improve the process [25].

\subsection{E-Based Assessment}

3E-based analysis is another method that is used to evaluate the sustainability of a machining process. The three Es stand for energy, environment, and economy [2]. These three approaches are different from LCA as it replaces society with high concern for energy consumption. Researchers have employed the 3E-based sustainability method in processes such as gas generation systems [26]. However, the same concept can also be used to evaluate the sustainability of a machining process. However, an assessment of the machining process alone is not enough to achieve sustainability targets. Thus, in this paper, sustainable guidelines are proposed for the $3 \mathrm{E}$ assessment method by including the engineering means for the evaluation of the used technology. After introducing all the guidelines from the sustainability indicators, a novel OPAI was proposed.

\section{Guidelines for Sustainable Machining}

A few years ago, Badurdeen et al. [27] studied the major metrics and indicators involved in the manufacturing process and proposed a guideline for sustainable manufacturing. The authors studied some of the indicators under major metrics. The same concept was used for our specific machining process to develop an extended guideline for the process. Production time, electrical power, energy consumption, cost, waste management, worker health, and the safety and environmental impacts were considered as the metrics for the manufacturing process. The guidelines for each metric are provided in the following sections.

\subsection{Production Time}

Production time is an important parameter that directly influences both electrical energy and resource consumption. Machining time during the turning process consists of the idle time and the setup time. It is worth mentioning that the setup time is the sum of the workpiece, cutting tool setup time, and handling time. The air cutting time is the time when the tool moves but does not cut the workpiece. Similarly, the cutting, tool change, and cooling and lubrication time are also part of the total machining time [28]. It is essential to highlight the indicators in the production time metrics. For example, the standby time is the sum of the setup time and the idle time. The setup time includes two stages, the cutting tool change stage and the workpiece handling stage. During the cutting time, the workpiece and cutting tool interact with each other, and material is removed by the cutting mechanism. Furthermore, other time factors, such as the transportation time, storage time, and cleaning and disposal time, also affect the overall sustainability of processes.

\subsection{Power and Energy Consumption}

The power demands from the different components of machine tools vary and it is tough to determine each component's demand. The power structures in the machining process change with the functionality states of the machine tools. However, in general, maximum power is consumed when all components of the machine tool are active. These components consume power in the functional stages of a machine tool. These stages are idle, set up, air cutting, cutting, tool change, and lubrication and cooling. Energy consumption is the second important metric considered under the guidelines of a sustainable machining process. Sustainability indicators related to energy consumption are considered in the guidelines and are shown in Table 1 . The measurements of sustainability indicators under the domain of energy consumption are described in detail in [22]. 
Table 1. Types of electrical and embodied energy consumptions and their indicators.

\begin{tabular}{|c|c|c|c|}
\hline Sustainability Factor & Sustainability Indicator & & Definition and Measurement Method \\
\hline \multirow{18}{*}{ Energy consumption, $\mathrm{E}$} & \multirow{9}{*}{ Electrical energy consumption } & $E_{s b}$ & $\begin{array}{l}\text { Energy consumption during the standby } \\
\text { stage }(\mathrm{kWh})\end{array}$ \\
\hline & & $E_{a}$ & $\begin{array}{l}\text { Energy consumption during the air cutting } \\
\text { stage, }(\mathrm{kWh})\end{array}$ \\
\hline & & $E_{c}$ & $\begin{array}{l}\text { Energy consumption during the cutting } \\
\text { stage, }(\mathrm{kWh})\end{array}$ \\
\hline & & $E_{t c}$ & $\begin{array}{l}\text { Energy consumption during the tool } \\
\text { change stage, }(\mathrm{kWh})\end{array}$ \\
\hline & & $E_{c o l}$ & $\begin{array}{l}\text { Energy consumption during the coolant } \\
\text { impingement, }(\mathrm{kWh})\end{array}$ \\
\hline & & $E_{l u b}$ & $\begin{array}{l}\text { Energy consumption during the lubricant } \\
\text { impingement, }(\mathrm{kWh})\end{array}$ \\
\hline & & $E_{C T}$ & Embodied energy of the cutting tool, $(\mathrm{kWh})$ \\
\hline & & $E_{m f}$ & $\begin{array}{l}\text { Electricity consumption to maintain the } \\
\text { facility environment, }(\mathrm{kWh})\end{array}$ \\
\hline & & $E_{t}$ & Transportation electricity consumption $(\mathrm{kJ})$ \\
\hline & \multirow{9}{*}{ Embodied energy consumption } & $E_{W p}$ & $\begin{array}{l}\text { Energy used to produce a unit volume of } \\
\text { material, (kJ) }\end{array}$ \\
\hline & & $E_{\text {oil }}$ & Embodied energy of the lubricant oil, (kJ) \\
\hline & & $E_{\text {emuls }}$ & Embodied energy of the emulsion, $(\mathrm{kJ})$ \\
\hline & & $E_{L N 2}$ & Embodied energy of the liquid nitrogen, $(\mathrm{kJ})$ \\
\hline & & $E_{c l}$ & Embodied energy of the cleaning stage, $(\mathrm{kJ})$ \\
\hline & & $E_{c c}$ & Energy used for the chip collection, (kJ) \\
\hline & & $E_{c f r}$ & $\begin{array}{l}\text { Energy required to recycle or recover the } \\
\text { cutting fluid, }(\mathrm{kJ})\end{array}$ \\
\hline & & $E_{m}$ & $\begin{array}{l}\text { Energy required to produce the cutting } \\
\text { fluid, }(\mathrm{kJ})\end{array}$ \\
\hline & & $E_{d}$ & $\begin{array}{l}\text { Energy required to dispose of all kinds of } \\
\text { parts and resources, }(\mathrm{kJ})\end{array}$ \\
\hline
\end{tabular}

\subsection{Cost}

One of the most important parameters for a performance evaluation is an economic comparison. The cost model presented in Kalpakjian et al. [29] showed major limitations. It described the production cost defined as the sum of the (1) machining cost, (2) tool change cost, and (3) cutting tool cost. However, costs due to non-cutting stages, particularly the lubrication stage and the advanced lubricooling process (MQL and cryogenic) were not addressed in detail. Hence, new cost models were developed to estimate the cost per part of sustainable and non-sustainable techniques. It is important to mention that the energy cost, machining cost, cutting tool cost, $\mathrm{LN}_{2}$ cost, $\mathrm{MQL}$ oil cost, emulsion cost, cleaning and disposal cost, and environmental cost should be considered.

In the present study, a lot of indicators were included for the cost metrics (Table 2). The general guidelines about costs demonstrate the details about all indicators of the cost measurement. Dry, MQL, Nanofluid MQL NFMQL, cryogenic, and hybrid CryoMQL assisted machining processes are the best examples of sustainable machining. Most of the indicators in all kinds of lubricooling-assisted machining processes are the same, such as the cutting tool cost, workpiece cost, and coolant cost. However, some cost components are specific for specific processes. For example, the cost of nanoparticles and the cost of nanofluid preparation is only used for NFMQL-assisted machining processes. Thus, guidelines for sustainable machining processes are given herein. The measurements of the sustainability indicators under the domain of energy consumption are described in detail in [2]. 
Table 2. Direct and indirect costs and their indicators.

\begin{tabular}{ccl}
\hline Sustainability Factor & \multicolumn{1}{c}{ Definition and Measurement Method } \\
\hline$C_{e}$ & Energy cost \\
$C_{m}$ & Machining cost \\
$C_{C T}$ & Cost of the cutting tool \\
$C_{L N_{2}}$ & Cost of the liquid nitrogen \\
$C_{e m u l s i o n}$ & Cost of the emulsion \\
$C_{o i l}$ & Cost of the base oil \\
$C_{n p}$ & Cost of the nanoparticles \\
$C_{e n v}$ & Environmental cost \\
$C_{W p}$ & Workpiece material cost \\
$C_{o i l}$ & Cost of the base oil \\
$C_{e m u l s i o n}$ & Emulsion cost \\
$C_{L N 2}$ & Cost of the liquid nitrogen \\
$C_{c l}$ & Cost of the cleaning stage \\
$C_{d}$ & Cost of the disposal \\
$C_{c c}$ & Cost of the chip collection \\
$C_{c f r}$ & Cost required to recycle or recover the cutting fluid \\
$C_{c f p}$ & Cost required to produce the cutting fluid \\
$C_{d r}$ & Cost required to dispose of all kinds of parts and \\
$C_{p g}$ & resources \\
$C_{t n}$ & Packaging-related cost \\
$C_{m t}$ & Training cost \\
$C_{j f}$ & Maintenance cost \\
& Cost of jigs/fixtures investment \\
\hline
\end{tabular}

\subsection{Waste Management}

Waste management is a very important process in industrial workshops, and ISO has imposed some standards to keep the workshop clean. Badurdeen et al. [27] discussed several indicators that are used to assess the sustainable value of waste management. However, some additional indicators were also considered in this study.

- $\quad$ Remanufactured scrap, $W M_{r m s}$

The $W M_{r m s}$ can be calculated from the ratio of the total mass of the remanufactured scrap $\left(m_{r m s}\right)$ and total mass of the scrap $\left(m_{s}\right)$. It can be defined as in Equation (1):

$$
W M_{r m s}=\frac{m_{r m s}}{m_{s}} .
$$

- $\quad$ Recycle chips, $W M_{r c}$

Recycle chips are quantified as the ratio of the total mass of recycled chips $\left(m_{r c}\right)$ to the mass of the total chips $\left(m_{\text {chip }}\right)$. It can be expressed as follows:

$$
W M_{r c}=\frac{m_{r c}}{m_{\text {chip }}} .
$$

- $\quad$ Disposed chips, $W M_{d c}$

During the recycling process, not all chips can be recycled, where some of those that do not qualify for recycling must be disposed of properly. Chip disposal can also be quantified as the ratio of total disposed chips $\left(m_{d c}\right)$ to the total mass of the chips:

$$
W M_{d c}=\frac{m_{d c}}{m_{c h i p}} .
$$

- $\quad$ Recycle scrap, $W M_{r c s}$ 
Cutting tools are a major part of recycled scraps. Tool holders and fixtures also face wear and tear, but they have relatively long lives. Thus, recycled scrap can be defined as the ratio of the total mass of all kinds of recycled scrap to the total mass of scrap:

$$
W M_{r c s}=\frac{m_{r c s}}{m_{\text {scrap }}} .
$$

- $\quad$ Disposed scrap, $W M_{d s}$

It is also a fact that not all scrap can be recycled or remanufactured. Scrap with extremely bad quality is separated and must be disposed of. The sustainable value of disposed scrap can be defined as the ratio of the total disposed scrap to the total mass of scrap, as shown in Equation (5):

$$
W M_{d s}=\frac{m_{d s}}{m_{s c r a p}} .
$$

- $\quad$ Mass of mist generation, $W M_{m g}$

During the MQL spray, a mist is generated, and quantification of the mist generation is necessary. It can be quantified as the ratio of the mist generated to the total mass of the spray, as follows:

$$
W M_{m g}=\frac{m_{m g}}{t_{m}} .
$$

- $\quad$ Recycle/recovered metalworking fluids, $W M_{R M W F}$

Unlike MQL, during a flood-assisted machining process, cutting fluid is not used one time and it can be recycled after its life. It can be expressed as the ratio of the recycled metalworking to the total mass of the metalworking fluid, as follows:

$$
W M_{R M W F}=\frac{m_{R M W F}}{m_{M W F}} .
$$

- $\quad$ Disposal of metalworking fluids, $W M_{D M W F}$

The disposal of MWFs is inevitable after their application in a workshop. The disposal of cutting fluids can be defined as the ratio of the disposed of cutting fluid to the total cutting fluid used:

$$
W M_{D M W F}=\frac{m_{D M W F}}{m_{M W F}} .
$$

- Idle electricity consumption, $W M_{i e}$

During the break time of the maintenance of a machine tool, unnecessary electrical appliances must be switched off to reduce electricity consumption. Work idle time during the shift time is also a major factor for idle electricity consumption. It can be demonstrated as the ratio of the idle electricity used to the total electricity used:

$$
W M_{i e}=\frac{E_{i}}{E_{t}}
$$

\subsection{Personal Health and Operational Safety}

It is also necessary to define guidelines for the personal health and safety of workers. Very little literature is published on the guidelines for worker health and safety for advanced machining processes. In this work, six indicators for worker health and safety were included.

- $\quad$ Noise level of the working environment $P_{n l}$ 
The noise levels in a workshop significantly affect workers' health. The indicator of the noise level can be classified into two parts. A noise level up to $90 \mathrm{~dB}$ is assigned 1 and a noise level of more than $90 \mathrm{~dB}$ is assigned value 2 . The quantification of the noise level helps to reduce noise pollution.

- Environmental conditions $P_{e c}$

The environmental conditions indicator $P_{e c}$ defines the working atmospheric conditions of workshops in metal processing industries. A sustainable value of $P_{e c}$ can also be assigned a 1 or a 2 . The values 1 or 2 are assigned according to the wet-bulb globe temperature. If the measured value of the temperature is up to $28{ }^{\circ} \mathrm{C}(82 \mathrm{~F})$, it is assigned a value of 1 , and a value of 2 is assigned for higher values. It is pertinent to mention that these values do not require previous criteria and are selected manually.

- Personal health index $P_{h i}$

The illumination level of the working environment is expressed in the personal health index $P_{h i}$. If the illumination level is less than 807 lux ( $75 \mathrm{fc}$ ), it is given a value of 1 , and if it is more than 807 lux $(75 \mathrm{fc})$, then a value of 2 is assigned.

- $\quad$ Total injuries rate $P_{\text {tir }}$

The total injuries rate is an alarming indicator under the personal health and operational safety metric. Several injuries per shift or per project are counted and its sustainable values are assigned according to the protection time according to ISO rules and regulations.

- Exposure to corrosive substances $O S_{c}$

This includes dust, mists, and the application of toxic chemicals. The exposure to corrosive substances can be explained as the exposure of all kinds of corrosive substances that are toxic to workers and the environment. It can be measured in incidents per person per processing time. Emissions that cause negative effects are scored as either 1,2, or 3, which depends upon the type of fluid used and the percentage concentration of nanoparticles used.

- Exposure to a high-temperature surface $O S_{h t s}$

During the machining of difficult-to-cut materials, the machinist has to face high-temperature surfaces. The sustainable values of this indicator are assigned according to the value of the temperature. Mostly, temperature values are categorized into two levels, where level 1 represents the temperature values less than $600{ }^{\circ} \mathrm{C}$ and temperature values that are more than $600{ }^{\circ} \mathrm{C}$ lie within the second category.

- $\quad$ Exposure to high-energy components $O S_{\text {hec }}$

The machine tool uses its maximum energy consumption during the machining process. In academia, mostly lower power rating machine tools are used. However, machine tools with total power up to $200 \mathrm{~kW}$ can be found in the industry. In this scenario, some components are energy-intensive and the worker may get injured while power measurements. It can be quantified as the injuries per person.

- Exposure to high-speed components/surfaces $O S_{h s s}$

Exposure to high-speed components/surfaces is an independent indicator. The sustainable value of this indicator can be assigned as either 1 or 2 , where it mainly depends upon the range of the cutting speed. For example, a cutting speed less than $900 \mathrm{rpm}$ is assigned a value of 1 and a cutting speed of more than $900 \mathrm{rpm}$ is assigned a value of 2 . 


\subsection{Environmental Impacts}

Environmental impacts are mostly characterized in terms of the $\mathrm{CO}_{2}$ emissions during the cutting process. These $\mathrm{CO}_{2}$ emissions are due to different components and/or different stages. The carbon emissions signature of the Nanjing power grid was used to find the sustainable values of the indicators. Some additional guidelines are as follows.

Direct and indirect activities that use energy also contribute to carbon emissions. As such, during the machining process, each process stage contributes to carbon emissions depending upon the corresponding process time. The total carbon emissions for the machining process is the sum of the carbon emissions due to computer numerical control (CNC)-machine-related activities and carbon emissions due to ancillary components. In this model, the carbon emissions for cleaning and disposal activities are also considered. The carbon emissions during each stage are calculated.

- Carbon emissions in the machining process

$\mathrm{CO}_{2}$ emissions due to the electrical energy consumption of a machine tool mimic the trends of the cutting energy. Carbon emissions are negative outcomes of power generation because power generation requires coal, oil, gas, and biomass [30]. The electrical energy produced by different types of fuels and its information is given in Table 3.

Table 3. The energy produced by various types of fuels.

\begin{tabular}{|c|c|c|c|c|}
\hline No. & Type of Fuel & 1 GJ of Heat Produced & Release $\Delta \mathbf{H}(\mathbf{k J})$ & Release $\mathrm{CO}_{2}$ \\
\hline 1 & Biomass & $\mathrm{CH}_{2} \mathrm{O}+\mathrm{O}_{2} \rightarrow \mathrm{CO}_{2}+\mathrm{H}_{2} \mathrm{O}$ & -440 & $100 \mathrm{~kg}$ \\
\hline 2 & Heavy oil & $\mathrm{C}_{20} \mathrm{H}_{42}+30 \mathrm{O}_{2} \rightarrow 20 \mathrm{CO}_{2}+21 \mathrm{H}_{2} \mathrm{O}$ & -13300 & $66 \mathrm{~kg}$ \\
\hline 3 & Coal & $\mathrm{C}+\mathrm{O}_{2} \rightarrow \mathrm{CO}_{2}$ & -394 & $112 \mathrm{~kg}$ \\
\hline 4 & Natural gas & $\begin{array}{c}\mathrm{CH}_{4}+2 \mathrm{O}_{2} \rightarrow \mathrm{CO}_{2}+2 \mathrm{H}_{2} \mathrm{O} \\
\Delta \mathrm{H}=\text { Enthalpy }\end{array}$ & -440 & $49 \mathrm{~kg}$ \\
\hline
\end{tabular}

The complete combustion of coal emits a huge amount of $\mathrm{CO}_{2}$. For example, the combustion of 1 ton of coal generates 2.86 tons of $\mathrm{CO}_{2}$. Various types of fuels used to produce electricity are depicted in Figure 3. Three power grids of different countries and their input fuel types are tabulated in Table 4.

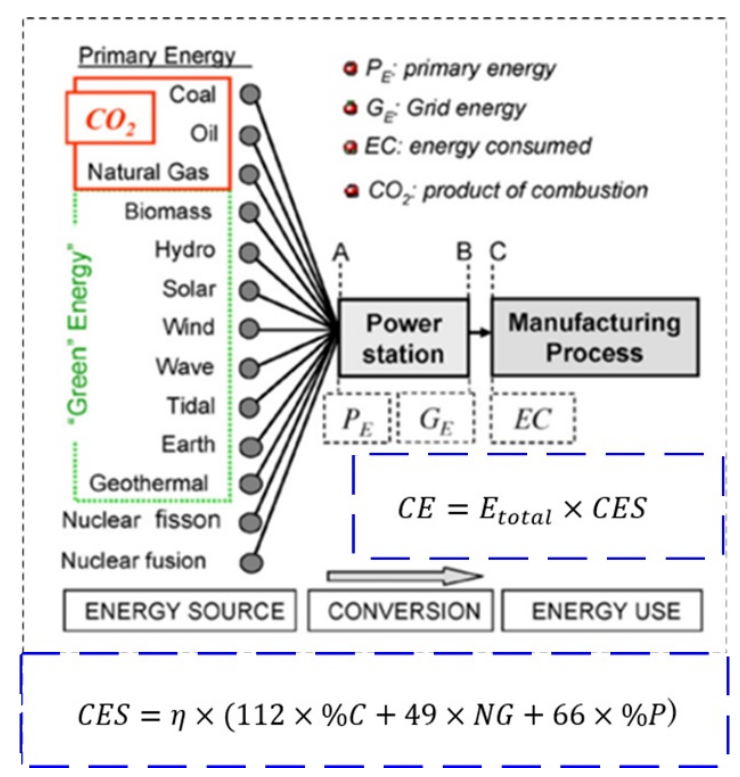

Figure 3. Primary energy supplies available [31]. 
Table 4. Three power grids of different countries and their input fuel type.

\begin{tabular}{cccc}
\hline Fuel Supply & Ontario (\%) & NSW (\%) & Nanjing \\
\hline Coal (C) & 19 & 83.9 & 73.09 \\
Natural Gas (NG) & 7 & 8.5 & 12.1 \\
Petroleum (P) & 0 & 0.3 & 0 \\
Biomass (B) & & & 6.92 \\
Solar (S) & 23 & 7.3 & 0.09 \\
Hydropower (H) & & & 5.96 \\
Wind (W) & & & \\
Geothermal (G) & & & \\
Earth (E) & & & 1.8 \\
Wave (Wa) & 51 & 100 & 100 \\
Tidal (T) & 100 & & \\
Nuclear (N) & & & \\
Total & &
\end{tabular}

The total carbon emitted in the process can be obtained by total energy consumption multiplying by carbon emission signature (CES).

$$
C E=E_{\text {total }} \times C E S
$$

where $C E$ is the amount of total Carbon Emission and $E_{\text {total }}$ is a total electrical energy consumption.

Usually, a local power grid has multiple primary energy sources and their abbreviations have been listed in Table 4. Every power grid has a specific CES, which mainly depends upon the input source used to produce the electricity. Before the assessment of the carbon emissions in the machining stages, it is essential to determine the carbon emission signature:

$$
\text { CES }=\eta \times(112 \times \% C+49 \times N G+66 \times \% P) .
$$

The carbon emissions per part due to the machining stages can be calculated as follows:

$$
C E_{m}=E_{m}(\mathrm{~J}) \times C E S\left(\frac{\mathrm{kgCO}_{2}}{\mathrm{~J}}\right),
$$

$E_{m}$ and $C E_{m}$ are electrical energy and its footprints for part production, respectively.

- Carbon emissions due to the cutting tool

As discussed earlier, the fabrication of cutting tools is an intensive process and environmental impacts of the fabrication of cutting tools can be obtained from the literature. The carbon emitted per part due to fabricating a cutting tool can be explained as:

$$
C E_{C T}=\frac{C F_{C T}}{T_{L}} \times t_{c}
$$

where $C F_{C T}$ is the carbon factor of the cutting tool and $T_{L}$ is life of cutting tool. Carbon emissions due to $\mathrm{LN}_{2}$.

Usually, it is considered that flood-assisted machining process is not environmentally friendly. However, if the environmental impacts of $L N_{2}$ are also included in the component-stage-based emissions-oriented (CSEO) model, the results could be significantly different. According to the authors' best knowledge, this is the first study to analyze the impacts of $L N_{2}$ production on the environment. The CE per part due to $L N_{2}$ can be defined as:

$$
C E_{L N_{2}}=C F_{L N_{2}} \times\left(t_{a}+t_{c}\right) \times Q_{L N_{2}}
$$

where $C F_{L N_{2}}$ is the carbon factor of liquid nitrogen, $t_{a}$ is an air cutting time and $Q_{L N_{2}}$ is flow rate of $L N_{2}$. 
- Carbon emissions due to MQL oil

Even though MQL oil is used in a minimal quantity and has low environmental impacts, it is used one time (non-recoverable) and it cannot be neglected if used in an industrial environment where the cutting processes may continue for several hours. Therefore, the $C E$ per part due to MQL oil can be defined as:

$$
C E_{M Q L}=C E_{M Q L} \times\left(t_{a}+t_{c}\right) \times Q_{M Q L} .
$$

- Carbon emissions due to emulsion

The emissions due to the application of emulsions during the machining process can be obtained as follows. Where $S$ denotes the flow rate and consumption of emulsion and $C F_{\text {emulsion }}$ is the carbon footprints of emulsion.

$$
C E_{\text {emulsion }}=C F_{\text {emulsion }} \times S \text {. }
$$

- Carbon emissions due to cleaning

The need for cleaning in the machining process is inevitable when emulsions are used. Environmental impacts or carbon emission factor of cleaning-related activities can be found in the literature. Hence, the $C E$ due to the cleaning stage is:

$$
C E_{c l}=C F_{c l} \times V
$$

It is important to mention that $C F_{c l}$ is a carbon factor of the cleaning process and $V$ is volume of material removed. The units of $C F$ vary according to the process.

- Carbon emissions due to disposal

ISO and some governmental organizations have stringent rules about the disposal of metalworking fluids used in the machining process. Thus, it is necessary to include the carbon emissions of the disposal stage $\left(C F_{\text {disposal }}\right)$ in the system's boundary:

$$
C E_{\text {disposal }}=C F_{\text {disposal }} \times S \text {. }
$$

- $\mathrm{CO}_{2}$ emissions indicator

Performance indicators are essential for studying the impact of the machining process on the environment. It is essential to determine the contribution of the cutting stages on the $\mathrm{CO}_{2}$ emitted per part produced. Thus, the fraction of $C E_{m}$ and carbon emission per part $\left(C E_{P}\right)$, called the $\mathrm{CO}_{2}$ emissions indicator $(C E I)$. It can be defined as:

$$
C E I=\frac{C E_{m}}{C E_{P}}
$$

- Cutting fluid distilling and condensing process $C E_{d c}$

It is a fact that cutting fluids are disposed of using various methods after use. Carbon emissions due to the distilling method used to dispose of the cutting fluids are measured in kilograms of $\mathrm{CO}_{2}$ per liter.

- Spindle lubricant oil production and disposal $C E_{s l}$

It is important to quantify the carbon emission due to the disposal of spindle lubricants. It is also measured in kilograms of $\mathrm{CO}_{2}$ per liter. 


\subsection{Water Consumption}

Thousands of gallons of water (Wa) are consumed in machining workshops monthly. This water is also considered to be an important metric for evaluating sustainability. The sustainability values of water consumption for sustainable machining processes have not been included in the guidelines before. Pervaiz et. al [32] published a state-of-the-art review study on water consumption in the machining process. The guidelines can be obtained in the authors' study. The quantification of this sustainable metric is mainly obtained in terms of the quantity of water used in the workshop.

\section{Energy-Integrated Heuristic Algorithm for Sustainable Machining}

In the past, a bulk of published literature can be a fund which only focuses on finding the optimal cutting condition of the process [33]. Different research groups tried to find optimal cutting conditions according to specific criteria and constraints. For example, researchers found the cutting parameters according to the best machining characteristics, such as the quality of the workpiece [34]. On the other hand, a second group of scholars optimized the cutting parameters for the minimum environmental impacts of the machining process [35]. A third group tried to minimize the machining costs to get economic benefits and optimized machining parameters [15]. Similarly, cutting parameters were also optimized for the best tool design and a longer tool life. However, optimal sustainable parameters obtained by considering machinability, economic, and environmental aspects are not studied in detail for advanced machining technologies.

Thus, the purpose of the proposed algorithm was to find the optimal machining parameters and their levels by considering the sustainability indicators explained in the last section (Section 4) and also the machinability characteristics. The proposed energy-integrated heuristic algorithm for sustainable machining offers the OPAI, which indicates the performance of the whole machining process in a holistic system. The proposed algorithm can deal with all kinds of qualitative and quantitative algorithms, regardless of whether they are considered to be "the higher the better" or "the lower the better." In summary, the proposed algorithm was based on a heuristic approach and is a very useful tool for solving multi-criteria decision making (MCDM) problems in sustainable machining. The methodology used to find the sustainability values of process/products can be found in Figure 2 . Several variables along with notations and explanations are explained in Table 5.

Table 5. List of the abbreviations used in the proposed algorithm.

\begin{tabular}{clll}
\hline Abbreviation & \multicolumn{1}{c}{ Definition } & Abbreviation & \multicolumn{1}{c}{ Definition } \\
\hline$n$ & Experiment number & $m$ & Metrics counter \\
$l$ & Cutting parameters level counter & $i$ & Indicator counter \\
$z$ & Machining response counter & $N$ & Total number of experiments \\
$M$ & Machining quality characteristics or total responses & $N M$ & Number of studied metrics \\
$N_{k}$ & Selection of the indicator for each response & $I_{m i}$ & Values of the sustainability indicator $(i)$ \\
$M r_{z}$ & Values of each machining response $(z)$ & $W_{z}$ & Weight for responses $(z)$ \\
$W_{m}$ & Weight for sustainable metrics & $W_{i}$ & Weight for indicator \\
$S F_{\operatorname{minz}}$ & Sustainability factor for each experiment number $(n)$ & $S I_{\operatorname{minz}}$ & Sustainability index for each experiment no. $(n)$ \\
$W S I_{\operatorname{minz}}$ & Weighted sustainability index for each cutting test $(n)$ & $O P I_{n}$ & Overall performance assessment indicator \\
\hline
\end{tabular}

\section{- $\quad$ Step 1: Calculation of the sustainability factor $\left(S F_{\operatorname{minz}}\right)$}

In the first step, experimental cutting test results are used along with sustainability indicators to get sustainability factors. Equations (20) and (21) define the sustainability factors. If each machining response $\left(M r_{z}\right)$ and sustainability indicator $\left(I_{m i}\right)$ have the same status, i.e., the lower the better or the higher the better, then the sustainability factor can be obtained as follows:

$$
S F_{\operatorname{minz}}=I_{\text {im }} \times M r_{z}
$$


However, if the machining response and sustainability indicator have opposite statuses, i.e., one is the higher the better, and the other is the lower the better, it can be calculated as follows:

$$
S F_{\text {minz }}=\frac{M r_{z}}{I_{i m}} .
$$

- $\quad$ Step 2: Calculation of the sustainability index $\left(S I_{\min z}\right)$

Sustainability factors for each experimental test are calculated. From the sustainability factors, the optimal sustainability factors are calculated and used to find the sustainability index of each test. In this step, normalization or scaling of each response is performed. If $S F_{\operatorname{minz}}$ is based on the lower the better, the sustainability index can be defined as:

$$
S I_{\operatorname{minz}}=\frac{\operatorname{Min}\left(S F_{\min z}\right)}{\operatorname{Max}\left(S F_{\min z}\right)} .
$$

However, if $S F_{\operatorname{minz}}$ is based on the higher the better, the sustainability index can be defined as:

$$
S I_{\min z}=\frac{S F_{\operatorname{minz}}}{\operatorname{Max} S F_{\min z}} .
$$

It is worth mentioning that the maximum value of $S I_{\min z}$ will be 1 . Once the $S I_{\operatorname{minz}}$ 's are obtained, different weights can be assigned to calculate the weighted sustainability index.

- Step 3: Calculation of the weighted sustainability index (WSI $\left.I_{k p i n}\right)$

Weights are assigned to the obtained $S I_{\text {minz }}$ 's, where the weight assignments are highly dependent upon the user's choice. Sometimes, all responses are considered equally; however, in industrial applications, some metrics are considered to be more important than others. For example, for aerospaceand defense-related products, surface quality is considered to be the most important metric compared to energy consumption. Weights can also be assigned according to expert opinion. In this work, the grey entropy method [36] was used to calculate the weights for $S I_{\text {minz }}$ :

$$
W S I_{\text {minz }}=W_{m} \times W_{z} \times W_{i} \times S I_{k p j n} .
$$

- Step 4: Calculation of the total weighted sustainability index (WSI $\left.I_{k p i n}\right)$

The last step of the algorithm is to calculate the total weighted sustainability index. It can be calculated using Equation (25):

$$
O P I_{n}=\sum_{m=1}^{N M} \times \sum_{i=1}^{N_{m}} \times \sum_{z=1}^{M} \times W S I_{m i n z} .
$$

\section{Assessment Model Validation (Case Studies)}

The proposed algorithm was validated using three case studies published by the current authors in the field of machining (external turning and milling) processes. The three case studies were chosen from MQL, nanofluid-based small quantity cooling lubrication SQCL, and cryogenic-assisted cooling approaches. The process parameters included the cutting speed, depth of cut, feed rate, and cooling mechanism. The optimal cutting parameters for the process were also found using the Non-Dominated Sorting Genetic Algorithm NSGA-II algorithm.

The OPAI was calculated to find the optimal and sustainable cutting parameters. The idea was to make sure the optimal conditions found from the proposed algorithm were consistent with the physical findings of the previous study. 


\subsection{Case Study 1: Nanofluid SQCL Assisted Milling Process}

In general, the case studies consisted of input process parameters, such as the feed rate, spindle speed, depth and width of the cut, and cooling technique. Similarly, machinability responses, such as the material removal rate, tool life, surface quality, and power and energy consumption were considered. In industrial environments, indicators are mostly given various weights according to their importance. However, in the present study, the authors assigned equal weights to avoid redundancy. In the selected case study [36], face milling experiments were performed on a CNC machine tool with a spindle power of $5.6 \mathrm{~kW}$ and a maximum rotation speed of $6000 \mathrm{rpm}$. AISI- 1045 steel was used as the work material. Surface roughness, material removal volume, and cutting energy were considered as three machining responses. The proposed algorithm was implemented to find the optimal cutting parameters based on the following assumptions:

- Environment, economy, and society (operator health and safety) were selected as three metrics.

- The sustainability indicator for the cost was the energy cost.

- The sustainability indicator for the environment was the $\mathrm{CO}_{2}$ emissions due to the electricity consumed by the machine tools.

- The sustainability indicators for the personal health and operation safety metric were $O S_{c}, O S_{h s c}$ and $O S_{\text {hec }}$.

The OPAI was calculated using the steps of the algorithms mentioned in Section 4. All the calculations are mentioned in Appendices A-C. These three appendices are only related to the first case study. The number 27 shows the total number of experiments. Appendices $\mathrm{A}-\mathrm{C}$ are designed to provide the calculations of the sustainability factors, calculations of $S I$, and the calculations of the WSI, respectively.

In the published study, only the grey relational grade (GRG) was used to find the optimal cutting parameters. However, the proposed algorithm considered both the machining and sustainability indicators simultaneously and found the OPAI values for the same experiments. Figure 4 shows the comparison of the OPAI with the GRG. The machining parameters used in this test were as follows: a spindle speed of $1200 \mathrm{rev} / \mathrm{min}$, a feed rate of $320 \mathrm{~mm} / \mathrm{min}$, a depth of cut of $0.5 \mathrm{~mm}$, and a width of cut of $15 \mathrm{~mm}$. The following output responses were achieved: Material Removal Rate MRR of $2400 \mathrm{~mm}^{3} / \mathrm{min}$, Surface Roughness SR of 2.29, and cutting energy of $53.98 \mathrm{~kJ}$. Similarly, the lowest OPAI was found for the experimental conditions of test 9, and the GRG was also found to be the lowest for the same cutting conditions. In this case study, the proposed algorithm predicted the identical cutting parameters for both the best and worst outcomes. The predictions for identical cutting parameters can be explained because very few indicators were selected for simplicity. However, the proposed algorithm can also predict different optimal cutting conditions, where this validation is left for future work. The idea was to open a new research direction and to integrate the sustainability indicators with the machining response to perform a holistic analysis.

\subsection{Case Study 2: Lubricooling-Assisted Approaches for the Turning Process}

Jamil et al. [3] conducted external turning experiments on a Ti-6Al-4V workpiece under hybrid alumina carbon-nanotubes $\mathrm{Al}_{2} \mathrm{O}_{3}-\mathrm{CNT}$ nanofluids and cryogenic cooling. The process parameter includes the depth of cut, cutting speed, feed rate, and cooling and lubrication approach. The cutting forces, temperature, and surface quality of the workpiece were measured to assess the performance of the lubricooling approaches. Two machining responses, namely, cutting forces and surface roughness, and four sustainability indicators, namely, cumulative energy demand (CED), carbon emission, production cost, and personal health index were considered as the responses in the algorithm. The design of the experiment and cutting conditions are shown in Table 3 of [3]. The OPAI of both lubricooling-assisted machining processes was calculated according to the steps mentioned in Section 5. The highest OPAI values of both lubricooling approaches were found at a cutting speed of $150 \mathrm{~m} / \mathrm{min}$ and a feed rate of 
$0.2 \mathrm{~mm} / \mathrm{rev}$ (Figure 5). Thus, it can be said that the machining of titanium alloys with cutting conditions of experiment 9 of the case study [3] was optimal and the most sustainable.

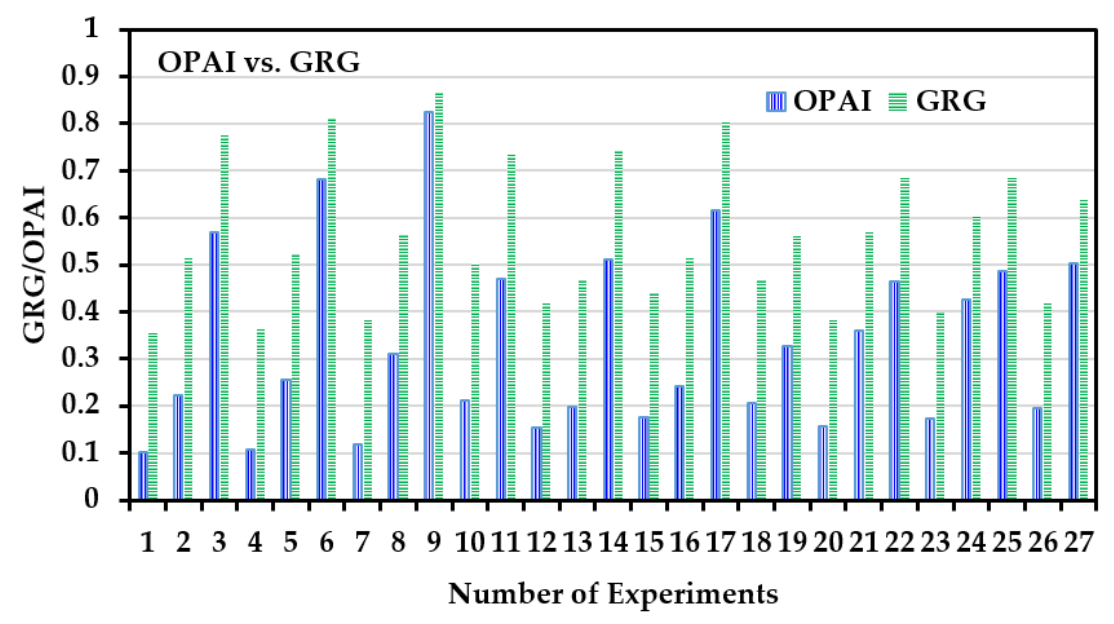

Figure 4. Comparison of the Overall Performance Assessment Indicator (OPAI) and the grey relational grade (GRG) for case study 1.

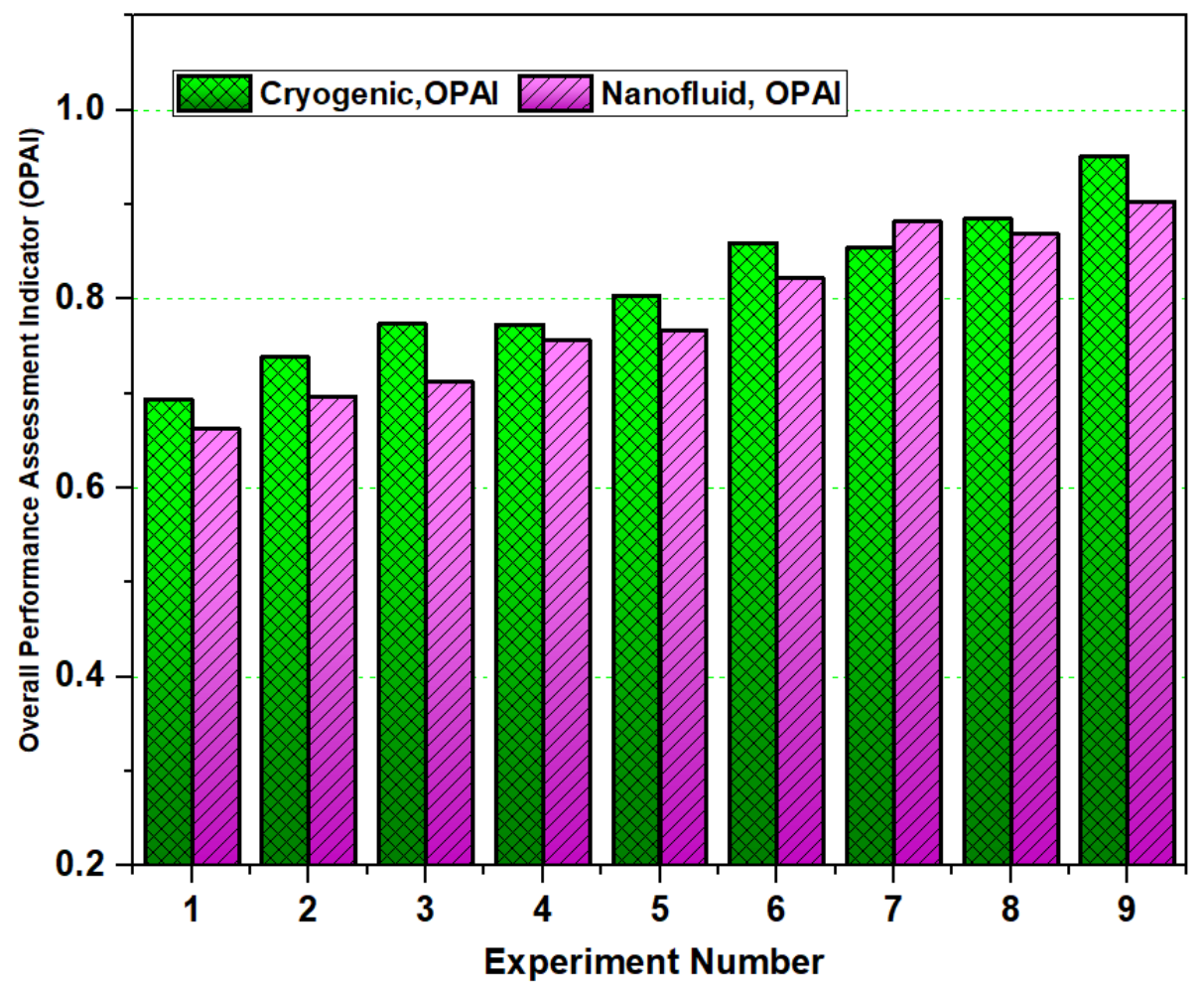

Figure 5. Calculation of the Overall Performance Assessment Indicator for case study 2.

\subsection{Case Study 3: Cryogenic-Assisted Machining Process}

Khan et al. [36] conducted three sets of experiments on various lubricooling (MQL, flood, and cryogenic) approaches to investigate their sustainability. The tool life and surface quality were measured as the studied machining quality characteristics. The cumulative energy demand, carbon emissions, production cost, and personal health index were measured as the sustainability indicators. Several sustainability factors (mentioned in Section 4.2) for energy consumption, cost, and carbon emission were included. The presented assessment algorithm was employed to evaluate the optimal cutting conditions that satisfied both the machining and sustainability characteristics. 
The OPAI of each lubricooling approach was calculated and shown in Figure 6. It was noted that the highest value of OPAI (i.e., 1) was obtained in experimental trial number 1 [36]. The experiment was performed at a cutting speed of $30 \mathrm{~m} / \mathrm{min}$, a feed rate of $0.1 \mathrm{~mm} / \mathrm{min}$, and a depth of cut of $0.8 \mathrm{~mm}$ using an MQL-assisted lubrication approach. The cutting tool wore quickly at higher cutting speeds; thus, the OPAI decreased from lower to higher cutting conditions.

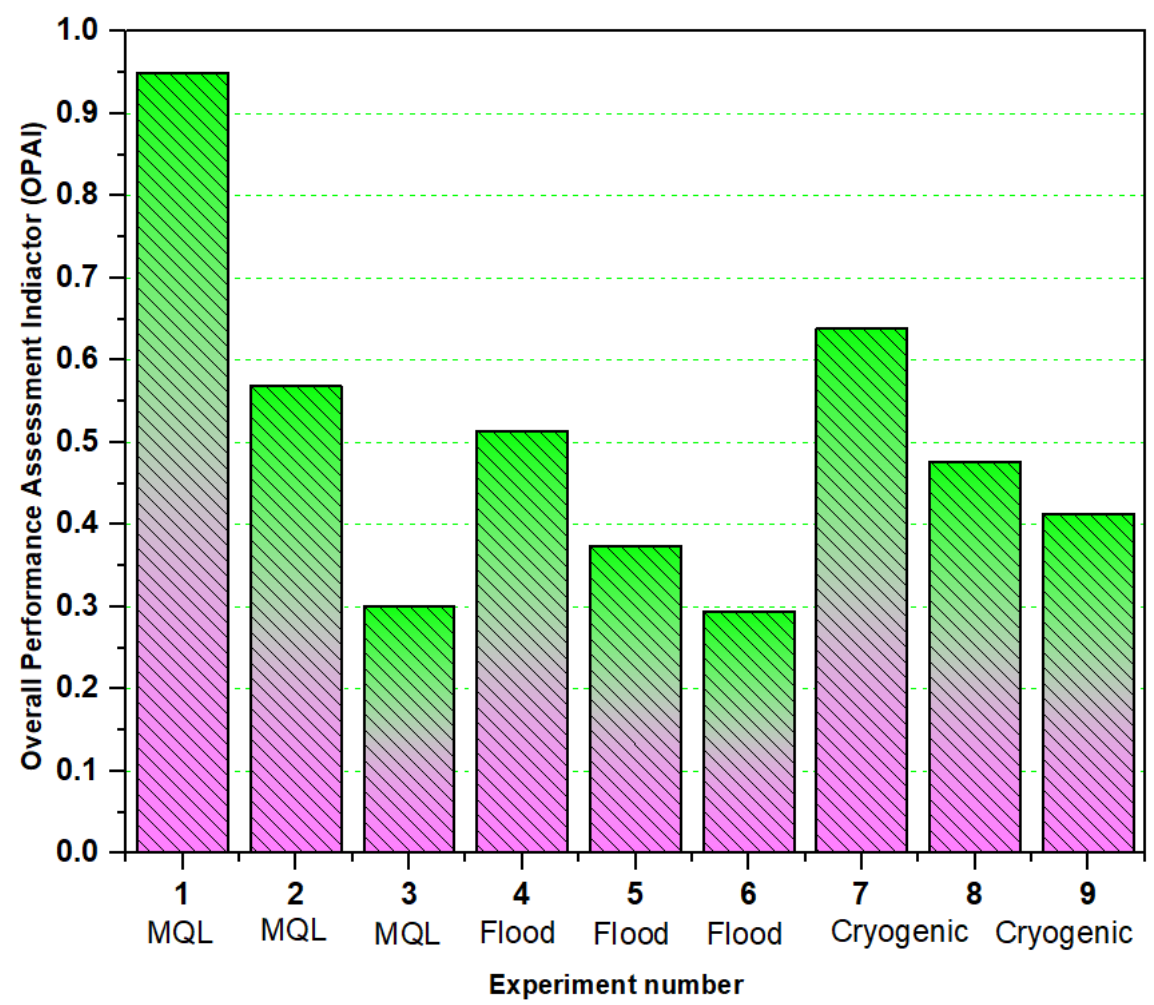

Figure 6. Weighted sustainability index of cryogenic $\mathrm{LN}_{2}$-assisted machining for case study 3.

\section{Conclusions}

In the present work, holistic sustainable guidelines were developed for cryogenic- and nanofluid-assisted MQL machining processes. Based on the guidelines, a heuristic algorithm was proposed, which not only addressed sustainability metrics but also incorporated the machinability characteristics. A set of new optimal cutting parameters were found based on both the machinability (measured in case studies) and sustainability indicators (added in the algorithm).

Seven major sustainability metrics (time, electric power, energy, cost, emission, waste, and water consumption) were considered in the proposed algorithm. From the sustainable guidelines, several indicators were evaluated under each metric.

A novel assessment indicator named the Overall Performance Assessment Indicator was introduced and verified from three different case studies. The results obtained from the first case study were in good agreement with the experimental results of the case study. In the second and third case studies, the optimal cutting parameters were found for the machinability and sustainability perspectives simultaneously. The proposed OPAI indicator was found to be extremely useful for achieving optimization in the mechanical machining processes. 


\section{Limitation and Future Trends}

There are some challenges that should be dealt with in the future. The qualitative indicators under sustainability guidelines received a specific quantitative score, which may vary in different industrial environments. Efforts should be made to make a unique score assignment mechanism. Second, data for some indicators, such as the fixture life or the cost incurred when disposing of chips were not available in detail, and manufacturers also lacked this type of data. This emphasizes the need for proper and detailed data collection to perform a holistic analysis. Another issue is that the influence of energy consumption on the economy and environment will vary from country to country. The price of electricity and the type of natural resources used to produce electricity are major factors that decide the impact.

Author Contributions: Conceptualization, A.M.K.; writing—original draft, A.M.K.; formal analysis, S.A., A.A., and M.K.G.; funding acquisition, A.A.; investigation, A.M.K. and M.J.; methodology, S.H.; project administration, M.M.; resources, A.M.K., M.K.G., and M.J.; software, M.K.G. and D.Y.P.; supervision, M.M.; validation, A.A., S.A., and D.Y.P.; visualization, A.M.K. and S.H.; writing-review and editing, S.A., A.A., and M.M. All authors have read and agreed to the published version of the manuscript.

Funding: This research was funded by the Researchers Supporting Project number (RSP-2020/256), King Saud University, Riyadh, Saudi Arabia.

Acknowledgments: The authors are thankful to King Saud University for funding this work through Researchers Supporting Project number (RSP-2020/256), King Saud University, Riyadh, Saudi Arabia.

Conflicts of Interest: The authors declare no conflict of interest. 
Appendix A

Table A1. OPAI Step 1: Calculation of the sustainability factors.

\begin{tabular}{|c|c|c|c|c|c|c|c|c|c|c|c|c|c|c|c|}
\hline \multirow[t]{2}{*}{ No. } & \multicolumn{5}{|c|}{ Sustainability Factor for MRR } & \multicolumn{5}{|c|}{ Sustainability Factor for Ra } & \multicolumn{5}{|c|}{ Sustainability Factor for Energy } \\
\hline & $M R R \times C E$ & MRRCost & MRR $\times$ Ostc & MRR $\times$ Oshss & $\mathrm{MRR} \times \mathbf{W f}$ & $\operatorname{Ra} \times \mathbf{C E}$ & $\operatorname{Ra} \times \operatorname{Cost}$ & Ra×Ostc & Ra $\times$ Oshss & $\operatorname{Ra} \times W f$ & Energy $\times C E$ & Energy $\times$ Cost & Energy $\times$ Ostc & Energy $\times$ Oshss & Energy $\times W f$ \\
\hline 1 & 0.0004 & 0.3247 & 0.0030 & 0.0091 & 0.0030 & 0.4562 & 353.6293 & 3.3000 & 9.9000 & 3.3000 & 74.0676 & $57,416.7566$ & 535.8020 & 1607.4060 & 535.8020 \\
\hline 2 & 0.0001 & 0.0420 & 0.0011 & 0.0034 & 0.0011 & 0.1407 & 109.1081 & 2.9500 & 8.8500 & 2.9500 & 8.8233 & 6839.7470 & 184.9290 & 554.7870 & 184.9290 \\
\hline 3 & 0.0000 & 0.0107 & 0.0006 & 0.0018 & 0.0006 & 0.0322 & 24.9624 & 1.4100 & 4.2300 & 1.4100 & 2.0216 & 1567.1227 & 88.5190 & 265.5570 & 88.5190 \\
\hline 4 & 0.0003 & 0.2104 & 0.0025 & 0.0074 & 0.0025 & 0.4211 & 326.3995 & 3.8300 & 11.4900 & 3.8300 & 46.8448 & $36,313.7760$ & 426.1090 & 1278.3270 & 426.1090 \\
\hline 5 & 0.0000 & 0.0270 & 0.0009 & 0.0028 & 0.0009 & 0.1458 & 113.0427 & 3.8700 & 11.6100 & 3.8700 & 5.5033 & 4266.1205 & 146.0500 & 438.1500 & 146.0500 \\
\hline 6 & 0.0000 & 0.0069 & 0.0005 & 0.0015 & 0.0005 & 0.0303 & 23.4605 & 1.6800 & 5.0400 & 1.6800 & 1.2578 & 975.0503 & 69.8230 & 209.4690 & 69.8230 \\
\hline 7 & 0.0002 & 0.1508 & 0.0021 & 0.0063 & 0.0021 & 0.3706 & 287.2946 & 3.9700 & 11.9100 & 3.9700 & 33.7780 & $26,184.4792$ & 361.8320 & 1085.4960 & 361.8320 \\
\hline 8 & 0.0000 & 0.0192 & 0.0008 & 0.0023 & 0.0008 & 0.1120 & 86.8211 & 3.5300 & 10.5900 & 3.5300 & 3.9018 & 3024.6193 & 122.9760 & 368.9280 & 122.9760 \\
\hline 9 & 0.0000 & 0.0045 & 0.0004 & 0.0013 & 0.0004 & 0.0319 & 24.7265 & 2.2900 & 6.8700 & 2.2900 & 0.7520 & 582.9408 & 53.9880 & 161.9640 & 53.9880 \\
\hline 10 & 0.0001 & 0.1021 & 0.0015 & 0.0030 & 0.0015 & 0.1574 & 122.0092 & 1.8100 & 3.6200 & 1.8100 & 29.3081 & $22,719.4620$ & 337.0420 & 674.0840 & 337.0420 \\
\hline 11 & 0.0000 & 0.0216 & 0.0008 & 0.0015 & 0.0008 & 0.0416 & 32.2563 & 1.1300 & 2.2600 & 1.1300 & 5.2557 & 4074.1993 & 142.7270 & 285.4540 & 142.7270 \\
\hline 12 & 0.0001 & 0.1087 & 0.0018 & 0.0036 & 0.0018 & 0.2677 & 207.5275 & 3.4700 & 6.9400 & 3.4700 & 23.0702 & $17,883.9078$ & 299.0310 & 598.0620 & 299.0310 \\
\hline 13 & 0.0001 & 0.0666 & 0.0012 & 0.0025 & 0.0012 & 0.1982 & 153.6743 & 2.8500 & 5.7000 & 2.8500 & 18.7531 & $14,537.2634$ & 269.6040 & 539.2080 & 269.6040 \\
\hline 14 & 0.0000 & 0.0140 & 0.0006 & 0.0012 & 0.0006 & 0.0413 & 32.0487 & 1.4100 & 2.8200 & 1.4100 & 3.3323 & 2583.1736 & 113.6480 & 227.2960 & 113.6480 \\
\hline 15 & 0.0001 & 0.0707 & 0.0015 & 0.0030 & 0.0015 & 0.2406 & 186.4882 & 3.9100 & 7.8200 & 3.9100 & 14.6727 & $11,374.1605$ & 238.4760 & 476.9520 & 238.4760 \\
\hline 16 & 0.0001 & 0.0445 & 0.0010 & 0.0021 & 0.0010 & 0.1405 & 108.9151 & 2.5500 & 5.1000 & 2.5500 & 11.7667 & 9121.4893 & 213.5590 & 427.1180 & 213.5590 \\
\hline 17 & 0.0000 & 0.0096 & 0.0005 & 0.0010 & 0.0005 & 0.0332 & 25.7292 & 1.3900 & 2.7800 & 1.3900 & 2.2099 & 1713.1375 & 92.5510 & 185.1020 & 92.5510 \\
\hline 18 & 0.0001 & 0.0483 & 0.0013 & 0.0025 & 0.0013 & 0.2053 & 159.1218 & 4.1200 & 8.2400 & 4.1200 & 9.6211 & 7458.2172 & 193.1090 & 386.2180 & 193.1090 \\
\hline 19 & 0.0001 & 0.0494 & 0.0010 & 0.0010 & 0.0010 & 0.1109 & 85.9947 & 1.7600 & 1.7600 & 1.7600 & 15.3985 & $11,936.7912$ & 244.3030 & 244.3030 & 244.3030 \\
\hline 20 & 0.0002 & 0.1935 & 0.0023 & 0.0023 & 0.0023 & 0.3658 & 283.5808 & 3.3300 & 3.3300 & 3.3300 & 46.7762 & $36,260.6170$ & 425.7970 & 425.7970 & 425.7970 \\
\hline 21 & 0.0000 & 0.0301 & 0.0009 & 0.0009 & 0.0009 & 0.1008 & 78.1726 & 2.3600 & 2.3600 & 2.3600 & 7.0769 & 5485.9969 & 165.6200 & 165.6200 & 165.6200 \\
\hline 22 & 0.0000 & 0.0319 & 0.0008 & 0.0008 & 0.0008 & 0.0585 & 45.3817 & 1.1700 & 1.1700 & 1.1700 & 9.7040 & 7522.4671 & 193.9390 & 193.9390 & 193.9390 \\
\hline 23 & 0.0002 & 0.1254 & 0.0019 & 0.0019 & 0.0019 & 0.3250 & 251.9028 & 3.7200 & 3.7200 & 3.7200 & 29.5760 & 22,927.1478 & 338.5790 & 338.5790 & 338.5790 \\
\hline 24 & 0.0000 & 0.0195 & 0.0007 & 0.0007 & 0.0007 & 0.0874 & 67.7730 & 2.5800 & 2.5800 & 2.5800 & 4.4508 & 3450.1967 & 131.3430 & 131.3430 & 131.3430 \\
\hline 25 & 0.0000 & 0.0223 & 0.0007 & 0.0007 & 0.0007 & 0.0585 & 45.3699 & 1.4100 & 1.4100 & 1.4100 & 6.6782 & 5176.8610 & 160.8860 & 160.8860 & 160.8860 \\
\hline 26 & 0.0001 & 0.0896 & 0.0016 & 0.0016 & 0.0016 & 0.2857 & 221.4482 & 3.8600 & 3.8600 & 3.8600 & 21.2290 & $16,456.5845$ & 286.8500 & 286.8500 & 286.8500 \\
\hline 27 & 0.0000 & 0.0135 & 0.0006 & 0.0006 & 0.0006 & 0.0770 & 59.6971 & 2.7600 & 2.7600 & 2.7600 & 3.0175 & 2339.1547 & 108.1470 & 108.1470 & 108.1470 \\
\hline
\end{tabular}




\section{Appendix B}

Table A2. OPAI Step 2: Calculation of the sustainability index.

\begin{tabular}{|c|c|c|c|c|c|c|c|c|c|c|c|c|c|c|c|}
\hline \multirow[t]{2}{*}{ No. } & \multicolumn{15}{|c|}{ Sustainability Index } \\
\hline & $\mathrm{MRR} \times \mathrm{CE}$ & MRR $\times$ Cost & MRR $\times$ Ostc & MRR $\times$ Oshss & $M R R \times W f$ & $\operatorname{Ra} \times C E$ & $\operatorname{Ra} \times \operatorname{Cost}$ & Ra $\times$ Ostc & Ra $\times$ Oshss & $\operatorname{Ra} \times \mathbf{W f}$ & Energy $\times C \mathrm{CE}$ & Energy $\times$ Cost & Energy $\times$ Ostc & Energy $\times$ Oshss & Energy $\times W f$ \\
\hline 1 & 0.0139 & 0.0139 & 0.1375 & 0.0688 & 0.1375 & 0.0663 & 0.0663 & 0.3424 & 0.1182 & 0.3424 & 0.0102 & 0.0102 & 0.1008 & 0.0673 & 0.1008 \\
\hline 2 & 0.1070 & 0.1070 & 0.3667 & 0.1833 & 0.3667 & 0.2150 & 0.2150 & 0.3831 & 0.1322 & 0.3831 & 0.0852 & 0.0852 & 0.2919 & 0.1949 & 0.2919 \\
\hline 3 & 0.4193 & 0.4193 & 0.6875 & 0.3438 & 0.6875 & 0.9398 & 0.9398 & 0.8014 & 0.2766 & 0.8014 & 0.3720 & 0.3720 & 0.6099 & 0.4072 & 0.6099 \\
\hline 4 & 0.0214 & 0.0214 & 0.1688 & 0.0844 & 0.1688 & 0.0719 & 0.0719 & 0.2950 & 0.1018 & 0.2950 & 0.0161 & 0.0161 & 0.1267 & 0.0846 & 0.1267 \\
\hline 5 & 0.1663 & 0.1663 & 0.4500 & 0.2250 & 0.4500 & 0.2075 & 0.2075 & 0.2920 & 0.1008 & 0.2920 & 0.1366 & 0.1366 & 0.3697 & 0.2468 & 0.3697 \\
\hline 6 & 0.6524 & 0.6524 & 0.8438 & 0.4219 & 0.8438 & 1.0000 & 1.0000 & 0.6726 & 0.2321 & 0.6726 & 0.5979 & 0.5979 & 0.7732 & 0.5163 & 0.7732 \\
\hline 7 & 0.0298 & 0.0298 & 0.2000 & 0.1000 & 0.2000 & 0.0817 & 0.0817 & 0.2846 & 0.0982 & 0.2846 & 0.0223 & 0.0223 & 0.1492 & 0.0996 & 0.1492 \\
\hline 8 & 0.2341 & 0.2341 & 0.5333 & 0.2667 & 0.5333 & 0.2702 & 0.2702 & 0.3201 & 0.1105 & 0.3201 & 0.1927 & 0.1927 & 0.4390 & 0.2931 & 0.4390 \\
\hline 9 & 1.0000 & 1.0000 & 1.0000 & 0.5000 & 1.0000 & 0.9488 & 0.9488 & 0.4934 & 0.1703 & 0.4934 & 1.0000 & 1.0000 & 1.0000 & 0.6677 & 1.0000 \\
\hline 10 & 0.0440 & 0.0440 & 0.2750 & 0.2063 & 0.2750 & 0.1923 & 0.1923 & 0.6243 & 0.3232 & 0.6243 & 0.0257 & 0.0257 & 0.1602 & 0.1604 & 0.1602 \\
\hline 11 & 0.2080 & 0.2080 & 0.5500 & 0.4125 & 0.5500 & 0.7273 & 0.7273 & 1.0000 & 0.5177 & 1.0000 & 0.1431 & 0.1431 & 0.3783 & 0.3789 & 0.3783 \\
\hline 12 & 0.0414 & 0.0414 & 0.2292 & 0.1719 & 0.2292 & 0.1130 & 0.1130 & 0.3256 & 0.1686 & 0.3256 & 0.0326 & 0.0326 & 0.1805 & 0.1808 & 0.1805 \\
\hline 13 & 0.0676 & 0.0676 & 0.3375 & 0.2531 & 0.3375 & 0.1527 & 0.1527 & 0.3965 & 0.2053 & 0.3965 & 0.0401 & 0.0401 & 0.2002 & 0.2006 & 0.2002 \\
\hline 14 & 0.3207 & 0.3207 & 0.6750 & 0.5063 & 0.6750 & 0.7320 & 0.7320 & 0.8014 & 0.4149 & 0.8014 & 0.2257 & 0.2257 & 0.4750 & 0.4758 & 0.4750 \\
\hline 15 & 0.0637 & 0.0637 & 0.2813 & 0.2109 & 0.2813 & 0.1258 & 0.1258 & 0.2890 & 0.1496 & 0.2890 & 0.0513 & 0.0513 & 0.2264 & 0.2267 & 0.2264 \\
\hline 16 & 0.1011 & 0.1011 & 0.4000 & 0.3000 & 0.4000 & 0.2154 & 0.2154 & 0.4431 & 0.2294 & 0.4431 & 0.0639 & 0.0639 & 0.2528 & 0.2532 & 0.2528 \\
\hline 17 & 0.4667 & 0.4667 & 0.8000 & 0.6000 & 0.8000 & 0.9118 & 0.9118 & 0.8129 & 0.4209 & 0.8129 & 0.3403 & 0.3403 & 0.5833 & 0.5843 & 0.5833 \\
\hline 18 & 0.0932 & 0.0932 & 0.3333 & 0.2500 & 0.3333 & 0.1474 & 0.1474 & 0.2743 & 0.1420 & 0.2743 & 0.0782 & 0.0782 & 0.2796 & 0.2800 & 0.2796 \\
\hline 19 & 0.0912 & 0.0912 & 0.4125 & 0.6188 & 0.4125 & 0.2728 & 0.2728 & 0.6420 & 0.6648 & 0.6420 & 0.0488 & 0.0488 & 0.2210 & 0.4427 & 0.2210 \\
\hline 20 & 0.0232 & 0.0232 & 0.1833 & 0.2750 & 0.1833 & 0.0827 & 0.0827 & 0.3393 & 0.3514 & 0.3393 & 0.0161 & 0.0161 & 0.1268 & 0.2540 & 0.1268 \\
\hline 21 & 0.1494 & 0.1494 & 0.4583 & 0.6875 & 0.4583 & 0.3001 & 0.3001 & 0.4788 & 0.4958 & 0.4788 & 0.1063 & 0.1063 & 0.3260 & 0.6530 & 0.3260 \\
\hline 22 & 0.1409 & 0.1409 & 0.5063 & 0.7594 & 0.5063 & 0.5170 & 0.5170 & 0.9658 & 1.0000 & 0.9658 & 0.0775 & 0.0775 & 0.2784 & 0.5576 & 0.2784 \\
\hline 23 & 0.0359 & 0.0359 & 0.2250 & 0.3375 & 0.2250 & 0.0931 & 0.0931 & 0.3038 & 0.3145 & 0.3038 & 0.0254 & 0.0254 & 0.1595 & 0.3194 & 0.1595 \\
\hline 24 & 0.2312 & 0.2312 & 0.5625 & 0.8438 & 0.5625 & 0.3462 & 0.3462 & 0.4380 & 0.4535 & 0.4380 & 0.1690 & 0.1690 & 0.4110 & 0.8234 & 0.4110 \\
\hline 25 & 0.2013 & 0.2013 & 0.6000 & 0.9000 & 0.6000 & 0.5171 & 0.5171 & 0.8014 & 0.8298 & 0.8014 & 0.1126 & 0.1126 & 0.3356 & 0.6722 & 0.3356 \\
\hline 26 & 0.0502 & 0.0502 & 0.2667 & 0.4000 & 0.2667 & 0.1059 & 0.1059 & 0.2927 & 0.3031 & 0.2927 & 0.0354 & 0.0354 & 0.1882 & 0.3770 & 0.1882 \\
\hline 27 & 0.3328 & 0.3328 & 0.6667 & 1.0000 & 0.6667 & 0.3930 & 0.3930 & 0.4094 & 0.4239 & 0.4094 & 0.2492 & 0.2492 & 0.4992 & 1.0000 & 0.4992 \\
\hline
\end{tabular}




\section{Appendix C}

Table A3. OPAI Step 3: Calculation of the weighted sustainability index.

\begin{tabular}{|c|c|c|c|c|c|c|c|c|c|c|c|c|c|c|c|}
\hline \multirow[t]{2}{*}{ No. } & \multicolumn{15}{|c|}{ Weighted Sustainability Index } \\
\hline & $\mathrm{MRR} \times \mathrm{CE}$ & MRR $\times$ Cost & MRR $\times$ Ostc & MRR $\times$ Oshss & $\mathbf{M R R} \times \mathbf{W f}$ & $\operatorname{Ra} \times C E$ & $\operatorname{Ra} \times \operatorname{Cost}$ & $\operatorname{Ra} \times$ Ostc & Ra $\times$ Oshss & $\mathrm{Ra} \times \mathrm{Wf}$ & Energy $\times C E$ & Energy $\times$ Cost & Energy $\times$ Ostc & Energy $\times$ Oshss & Energy $\times W f$ \\
\hline 1 & 0.0008 & 0.0008 & 0.0084 & 0.0042 & 0.0084 & 0.0040 & 0.0040 & 0.0207 & 0.0071 & 0.0207 & 0.0008 & 0.0008 & 0.0079 & 0.0053 & 0.0079 \\
\hline 2 & 0.0065 & 0.0065 & 0.0224 & 0.0112 & 0.0224 & 0.0130 & 0.0130 & 0.0232 & 0.0080 & 0.0232 & 0.0067 & 0.0067 & 0.0229 & 0.0153 & 0.0229 \\
\hline 3 & 0.0256 & 0.0256 & 0.0420 & 0.0210 & 0.0420 & 0.0568 & 0.0568 & 0.0485 & 0.0167 & 0.0485 & 0.0292 & 0.0292 & 0.0479 & 0.0320 & 0.0479 \\
\hline 4 & 0.0013 & 0.0013 & 0.0103 & 0.0052 & 0.0103 & 0.0043 & 0.0043 & 0.0178 & 0.0062 & 0.0178 & 0.0013 & 0.0013 & 0.0099 & 0.0066 & 0.0099 \\
\hline 5 & 0.0102 & 0.0102 & 0.0275 & 0.0137 & 0.0275 & 0.0126 & 0.0126 & 0.0177 & 0.0061 & 0.0177 & 0.0107 & 0.0107 & 0.0290 & 0.0194 & 0.0290 \\
\hline 6 & 0.0398 & 0.0398 & 0.0515 & 0.0258 & 0.0515 & 0.0605 & 0.0605 & 0.0407 & 0.0140 & 0.0407 & 0.0469 & 0.0469 & 0.0607 & 0.0405 & 0.0607 \\
\hline 7 & 0.0018 & 0.0018 & 0.0122 & 0.0061 & 0.0122 & 0.0049 & 0.0049 & 0.0172 & 0.0059 & 0.0172 & 0.0017 & 0.0017 & 0.0117 & 0.0078 & 0.0117 \\
\hline 8 & 0.0143 & 0.0143 & 0.0326 & 0.0163 & 0.0326 & 0.0163 & 0.0163 & 0.0194 & 0.0067 & 0.0194 & 0.0151 & 0.0151 & 0.0345 & 0.0230 & 0.0345 \\
\hline 9 & 0.0610 & 0.0610 & 0.0610 & 0.0305 & 0.0610 & 0.0574 & 0.0574 & 0.0298 & 0.0103 & 0.0298 & 0.0785 & 0.0785 & 0.0785 & 0.0524 & 0.0785 \\
\hline 10 & 0.0027 & 0.0027 & 0.0168 & 0.0126 & 0.0168 & 0.0116 & 0.0116 & 0.0378 & 0.0195 & 0.0378 & 0.0020 & 0.0020 & 0.0126 & 0.0126 & 0.0126 \\
\hline 11 & 0.0127 & 0.0127 & 0.0336 & 0.0252 & 0.0336 & 0.0440 & 0.0440 & 0.0605 & 0.0313 & 0.0605 & 0.0112 & 0.0112 & 0.0297 & 0.0297 & 0.0297 \\
\hline 12 & 0.0025 & 0.0025 & 0.0140 & 0.0105 & 0.0140 & 0.0068 & 0.0068 & 0.0197 & 0.0102 & 0.0197 & 0.0026 & 0.0026 & 0.0142 & 0.0142 & 0.0142 \\
\hline 13 & 0.0041 & 0.0041 & 0.0206 & 0.0155 & 0.0206 & 0.0092 & 0.0092 & 0.0240 & 0.0124 & 0.0240 & 0.0031 & 0.0031 & 0.0157 & 0.0157 & 0.0157 \\
\hline 14 & 0.0196 & 0.0196 & 0.0412 & 0.0309 & 0.0412 & 0.0443 & 0.0443 & 0.0485 & 0.0251 & 0.0485 & 0.0177 & 0.0177 & 0.0373 & 0.0374 & 0.0373 \\
\hline 15 & 0.0039 & 0.0039 & 0.0172 & 0.0129 & 0.0172 & 0.0076 & 0.0076 & 0.0175 & 0.0090 & 0.0175 & 0.0040 & 0.0040 & 0.0178 & 0.0178 & 0.0178 \\
\hline 16 & 0.0062 & 0.0062 & 0.0244 & 0.0183 & 0.0244 & 0.0130 & 0.0130 & 0.0268 & 0.0139 & 0.0268 & 0.0050 & 0.0050 & 0.0198 & 0.0199 & 0.0198 \\
\hline 17 & 0.0285 & 0.0285 & 0.0488 & 0.0366 & 0.0488 & 0.0551 & 0.0551 & 0.0492 & 0.0255 & 0.0492 & 0.0267 & 0.0267 & 0.0458 & 0.0459 & 0.0458 \\
\hline 18 & 0.0057 & 0.0057 & 0.0203 & 0.0153 & 0.0203 & 0.0089 & 0.0089 & 0.0166 & 0.0086 & 0.0166 & 0.0061 & 0.0061 & 0.0219 & 0.0220 & 0.0219 \\
\hline 19 & 0.0056 & 0.0056 & 0.0252 & 0.0378 & 0.0252 & 0.0165 & 0.0165 & 0.0388 & 0.0402 & 0.0388 & 0.0038 & 0.0038 & 0.0173 & 0.0348 & 0.0173 \\
\hline 20 & 0.0014 & 0.0014 & 0.0112 & 0.0168 & 0.0112 & 0.0050 & 0.0050 & 0.0205 & 0.0212 & 0.0205 & 0.0013 & 0.0013 & 0.0100 & 0.0199 & 0.0100 \\
\hline 21 & 0.0091 & 0.0091 & 0.0280 & 0.0420 & 0.0280 & 0.0182 & 0.0182 & 0.0290 & 0.0300 & 0.0290 & 0.0083 & 0.0083 & 0.0256 & 0.0513 & 0.0256 \\
\hline 22 & 0.0086 & 0.0086 & 0.0309 & 0.0464 & 0.0309 & 0.0313 & 0.0313 & 0.0584 & 0.0605 & 0.0584 & 0.0061 & 0.0061 & 0.0219 & 0.0438 & 0.0219 \\
\hline 23 & 0.0022 & 0.0022 & 0.0137 & 0.0206 & 0.0137 & 0.0056 & 0.0056 & 0.0184 & 0.0190 & 0.0184 & 0.0020 & 0.0020 & 0.0125 & 0.0251 & 0.0125 \\
\hline 24 & 0.0141 & 0.0141 & 0.0343 & 0.0515 & 0.0343 & 0.0209 & 0.0209 & 0.0265 & 0.0274 & 0.0265 & 0.0133 & 0.0133 & 0.0323 & 0.0646 & 0.0323 \\
\hline 25 & 0.0123 & 0.0123 & 0.0366 & 0.0549 & 0.0366 & 0.0313 & 0.0313 & 0.0485 & 0.0502 & 0.0485 & 0.0088 & 0.0088 & 0.0263 & 0.0528 & 0.0263 \\
\hline 26 & 0.0031 & 0.0031 & 0.0163 & 0.0244 & 0.0163 & 0.0064 & 0.0064 & 0.0177 & 0.0183 & 0.0177 & 0.0028 & 0.0028 & 0.0148 & 0.0296 & 0.0148 \\
\hline 27 & 0.0203 & 0.0203 & 0.0407 & 0.0610 & 0.0407 & 0.0238 & 0.0238 & 0.0248 & 0.0256 & 0.0248 & 0.0196 & 0.0196 & 0.0392 & 0.0785 & 0.0392 \\
\hline
\end{tabular}




\section{References}

1. Hegab, H.A.; Darras, B.; Kishawy, H.A. Towards sustainability assessment of machining processes. J. Clean. Prod. 2018, 170, 694-703. [CrossRef]

2. Khan, A.M.; Jamil, M.; Mia, M.; He, N.; Zhao, W.; Gong, L. Sustainability-based performance evaluation of hybrid nanofluid assisted machining. J. Clean. Prod. 2020, 257, 120541. [CrossRef]

3. Jamil, M.; Khan, A.M.; Hegab, H.; Gong, L.; Mia, M.; Gupta, M.K.; He, N. Effects of hybrid Al2O3-CNT nanofluids and cryogenic cooling on machining of Ti-6Al-4V. Int. J. Adv. Manuf. Technol. 2019. [CrossRef]

4. Said, Z.; Gupta, M.; Hegab, H.; Arora, N.; Khan, A.M.; Jamil, M.; Bellos, E. A comprehensive review on minimum quantity lubrication (MQL) in machining processes using nano-cutting fluids. Int. J. Adv. Manuf. Technol. 2019, 105, 2057-2086. [CrossRef]

5. Jamil, M.; Khan, A.M.; He, N.; Li, L.; Iqbal, A.; Mia, M. Evaluation of machinability and economic performance in cryogenic-assisted hard turning of $\alpha-\beta$ titanium: A step towards sustainable manufacturing. Mach. Sci. Technol. 2019. [CrossRef]

6. Jayal, A.D.; Badurdeen, F.; Dillon, O.W.; Jawahir, I.S. Sustainable manufacturing: Modeling and optimization challenges at the product, process and system levels. CIRP J. Manuf. Sci. Technol. 2010, 2, 144-152. [CrossRef]

7. Badurdeen, F.; Iyengar, D.; Goldsby, T.J.; Metta, H.; Gupta, S.; Jawahir, I.S. Extending total life-cycle thinking to sustainable supply chain design. Int. J. Prod. Lifecycle Manag. 2009. [CrossRef]

8. Joshi, K.; Venkatachalam, A.; Jawahir, I.S. A new methodology for transforming 3R concept into 6R concept for improved product sustainability. In Proceedings of the IV Global Conference on Sustainable Product Development and Life Cycle Engineering, Sao Paulo, Brazil, 3-6 October 2006; pp. 3-6.

9. Jawahir, I.S.; Dillon, O.W.; Rouch, K.E.; Joshi, K.J.; Venkatachalam, A.; Jaafar, I.H. Total life-cycle considerations in product design for sustainability: A framework for comprehensive evaluation. In Proceedings of the 10th International Research/Expert Conference "Trends in the Development of Machinery and Associated Technology" TMT, Barcelona, Spain, 11-15 September 2006.

10. Feng, S.C.; Joung, C.; Li, G. Development overview of sustainable manufacturing metrics. In Proceedings of the 17th CIRP International Conference on Life Cycle Engineering 2010, Hefei, China, 19-21 May 2010.

11. Fiksel, J.; McDaniel, J.; Spitzleyn, D. Measuring Product Sustainability. J. Sustain. Prod. Des. 1998, 7-18.

12. Pusavec, F.; Kopac, J. Achieving and implementation of sustainability principles in machining processes. Adv. Prod. Eng. Manag. 2009, 3, 58-69.

13. Reich-Weiser, C.; Vijayaraghavan, A.; Dornfeld, D.A. Metrics for Sustainable Manufacturing. In ASME 2008 International Manufacturing Science and Engineering Conference; ASME: New York, NY, USA, 2008; Volume 1, pp. 327-335.

14. Peralta Álvarez, M.E.; Marcos Bárcena, M.; Aguayo González, F. On the sustainability of machining processes. Proposal for a unified framework through the triple bottom-line from an understanding review. J. Clean. Prod. 2017, 142, 3890-3904.

15. Priarone, P.C.; Robiglio, M.; Settineri, L. On the concurrent optimization of environmental and economic targets for machining. J. Clean. Prod. 2018, 190, 630-644. [CrossRef]

16. Khanna, N.; Agrawal, C.; Gupta, M.K.; Song, Q.; Singla, A.K. Sustainability and machinability improvement of Nimonic-90 using indigenously developed green hybrid machining technology. J. Clean. Prod. 2020. [CrossRef]

17. Khanna, N.; Airao, J.; Gupta, M.K.; Song, Q.; Liu, Z.; Mia, M.; Maruda, R.; Krolczyk, G. Optimization of power consumption associated with surface roughness in ultrasonic assisted turning of Nimonic-90 using hybrid particle swarm-simplex method. Materials 2019, 12, 3418. [CrossRef]

18. Agrawal, C.; Khanna, N.; Gupta, M.K.; Kaynak, Y. Sustainability assessment of in-house developed environment-friendly hybrid techniques for turning Ti-6Al-4V. Sustain. Mater. Technol. 2020. [CrossRef]

19. Khan, A.M.; Ning, H.; Muhammad, J.; Raza, S.M. Energy characterization and energy-saving strategies in sustainable machining processes: A state-of-the-art review. J. Prod. Syst. Manuf. Sci. 2020, 2, 3-17.

20. Mia, M.; Gupta, M.K.; Lozano, J.A.; Carou, D.; Pimenov, D.Y.; Królczyk, G.; Khan, A.M.; Dhar, N.R. Multi-objective optimization and life cycle assessment of eco-friendly cryogenic N2 assisted turning of Ti-6Al-4V. J. Clean. Prod. 2019. [CrossRef] 
21. Singh, R.; Dureja, J.S.; Dogra, M.; Kumar Gupta, M.; Jamil, M.; Mia, M. Evaluating the sustainability pillars of energy and environment considering carbon emissions under machining ofTi-3Al-2.5 V. Sustain. Energy Technol. Assessments 2020. [CrossRef]

22. Khan, A.M.; Gupta, M.K.; Hegab, H.; Jamil, M.; Mia, M.; He, N.; Song, Q.; Liu, Z.; Pruncu, C.I. Energy-based cost integrated modelling and sustainability assessment of Al-GnP hybrid nanofluid assisted turning of AISI52100 steel. J. Clean. Prod. 2020, 257, 120502. [CrossRef]

23. Khan, A.M.; He, N.; Zhao, W.; Jamil, M.; Xia, H.; Meng, L.; Gupta, M.K. Cryogenic-LN 2 and conventional emulsion assisted machining of hardened steel: Comparison from sustainability perspective. Proc. Inst. Mech. Eng. Part B J. Eng. Manuf. 2020, 095440542097199. [CrossRef]

24. NACFAM National Council for Advanced Manufacturing (NACFAM) (2012) Sustainable manufacturing. Available online: http://www.nacfam.org/PolicyInitiatives/SustainableManufacturing/tabid/64/Default.aspx. (accessed on 20 December 2012).

25. Simboli, A.; Raggi, A.; Rosica, P. Life cycle assessment of process eco-innovations in an SME automotive supply network. Sustainability 2015, 7, 13761-13776. [CrossRef]

26. Ng, K.S.; Martinez Hernandez, E. A systematic framework for energetic, environmental and economic (3E) assessment and design of polygeneration systems. Chem. Eng. Res. Des. 2016. [CrossRef]

27. Badurdeen, F.; Shuaib, M.A.; Lu, T.; Jawahir, I.S. Sustainable value creation in manufacturing at product and process levels: Metrics-based evaluation. In HandBook of Manufacturing Engineering and Technology; Springer: Berlin, Germany, 2015; ISBN 9781447146704.

28. Khan, A.M.; Jamil, M.; Ul Haq, A.; Hussain, S.; Meng, L.; He, N. Sustainable machining. Modeling and optimization of temperature and surface roughness in the milling of AISI D2 steel. Ind. Lubr. Tribol. 2018. [CrossRef]

29. Kalpakjian, S.; Schmid, S. Manufacturing Engineering and Technology, 6th ed.; Addision-Wesley Publishing Company Inc.: Boston, MA, USA, 2006; ISBN 0133128741.

30. Wenzel, H.; Hauschild, M.; Alting, L.; Overcash, M. Environmental Assessment of Products: Volume 1: Methodology, tools and case studies in product. Int. J. Life Cycle Assess. 1999. [CrossRef]

31. Jeswiet, J.; Kara, S. Carbon emissions and CES ${ }^{\mathrm{TM}}$ in manufacturing. CIRP Ann. Manuf. Technol. 2008. [CrossRef]

32. Pervaiz, S.; Kannan, S.; Kishawy, H.A. An extensive review of the water consumption and cutting fluid based sustainability concerns in the metal cutting sector. J. Clean. Prod. 2018, 197, 134-153.

33. Khan, A.M.; Jamil, M.; Salonitis, K.; Sarfraz, S.; Zhao, W.; He, N.; Mia, M.; Zhao, G.L. Multi-objective optimization of energy consumption and surface quality in nanofluid SQCl assisted face milling. Energies 2019, 12, 710. [CrossRef]

34. Jamil, M.; Khan, A.M.; Gupta, M.K.; Mia, M.; He, N.; Li, L.; Sivalingam, V. Influence of $\mathrm{CO}_{2}$-snow and subzero MQL on thermal aspects in the machining of Ti-6Al-4V. Appl. Therm. Eng. 2020, 177, 115480. [CrossRef]

35. Yi, Q.; Li, C.; Tang, Y.; Chen, X. Multi-objective parameter optimization of CNC machining for low carbon manufacturing. J. Clean. Prod. 2015. [CrossRef]

36. Khan, A.M.; He, N.; Li, L.; Zhao, W.; Jamil, M. Analysis of Productivity and Machining Efficiency in Sustainable Machining of Titanium Alloy. Procedia Manuf. 2020, 43, 111-118. [CrossRef]

Publisher's Note: MDPI stays neutral with regard to jurisdictional claims in published maps and institutional affiliations.

(C) 2020 by the authors. Licensee MDPI, Basel, Switzerland. This article is an open access article distributed under the terms and conditions of the Creative Commons Attribution (CC BY) license (http://creativecommons.org/licenses/by/4.0/). 